Review

\title{
Advanced Shape Memory Technology to Reshape Product Design, Manufacturing and Recycling
}

\author{
Wen Guang Yang ${ }^{1}$, Haibao Lu ${ }^{2}$, Wei Min Huang ${ }^{3{ }^{*} *}$, Hang Jerry Qi ${ }^{4}$, Xue Lian Wu ${ }^{5}$ \\ and Ke Yuan Sun ${ }^{1}$ \\ 1 Nanjing Comp Tech Composites Co., Ltd., Nanjing 211162, China; \\ E-Mails: Kente@263.net (W.G.Y.); frank.sun@njcomptech.com (K.Y.S.) \\ 2 Science and Technology on Advanced Composites in Special Environments Laboratory, \\ Harbin Institute of Technology, Harbin 150080, China; E-Mail: lvbuwei1981@163.com \\ 3 School of Mechanical and Aerospace Engineering, Nanyang Technological University, \\ 50 Nanyang Avenue, 639798 Singapore, Singapore
}

4 School of Mechanical Engineering, Georgia Institute of Technology, Atlanta, GA 30332, USA; E-Mail: qih@me.gatech.edu

5 School of Mechanical Engineering, Jiangsu University, 301 Xuefu Road, Zhenjiang 212013, China; E-Mail:wxlmgy@126.com

* Author to whom correspondence should be addressed; E-Mail: mwmhuang@ntu.edu.sg; Tel.: +65-6790-4859; Fax: +65-6792-4062.

Received: 31 May 2014; in revised form: 25 July 2014 / Accepted: 12 August 2014 /

Published: 22 August 2014

\begin{abstract}
This paper provides a brief review on the advanced shape memory technology (ASMT) with a focus on polymeric materials. In addition to introducing the concept and fundamentals of the ASMT, the potential applications of the ASMT either alone or integrated with an existing mature technique (such as, 3D printing, quick response (QR) code, lenticular lens) and phenomena (e.g., wrinkling and stress-enhanced swelling effect) in product design, manufacturing, and recycling are demonstrated. It is concluded that the ASMT is indeed able to provide a range of powerful approaches to reshape part of the life cycle or the whole life cycle of products.
\end{abstract}

Keywords: shape memory effect; shape memory technology; design; manufacturing; recycling 


\section{Introduction}

The shape memory effect (SME) refers to the capability of a material to recover its original shape only when the right stimulus is applied [1-4]. Such a phenomenon is different from the shape change effect (SCE), in which a material responses to the applied stimulus in a linear or nonlinear manner with or without a hysteresis $[5,6]$. A higher energy barrier between the deformed shape, which is temporary, and the original shape, which is permanent, is the cause of the SME [7,8].

It should be pointed out that according to the working conditions and the actually applied stimulus, a material may show the SME, so that it is considered as a shape memory material (SMM), or may function as a shape change material (SCM), and, thus, it has the SCE. For instance, for a piece of dry hydrogel, in which the water content is low [9], on the one hand, it has the heating-responsive SME as many polymers; on the other hand, upon wetting in water, it swells and, hence, shows the water-responsive SCE. Although the term of shape memory technology (SMT) was started to be mentioned in early 1990s, it was mainly meant for shape memory alloys (SMAs) and associated techniques for their engineering applications at that time [6]. Recent development in shape memory polymers (SMPs) has revealed that the heating/chemo-responsive SME is actually an intrinsic feature of most polymeric materials, if not all [7]. For example, as shown in Figure 1, after finger impression, the piece of styrofoam, which has a glass transition temperature $\left(T_{\mathrm{g}}\right)$ about $100{ }^{\circ} \mathrm{C}$, is able to fully recover its original flat surface shape upon heating in boiling water.

Figure 1. The shape memory effect (SME) in styrofoam. (a) after finger impression at room temperature; (b) after heating in boiling water.

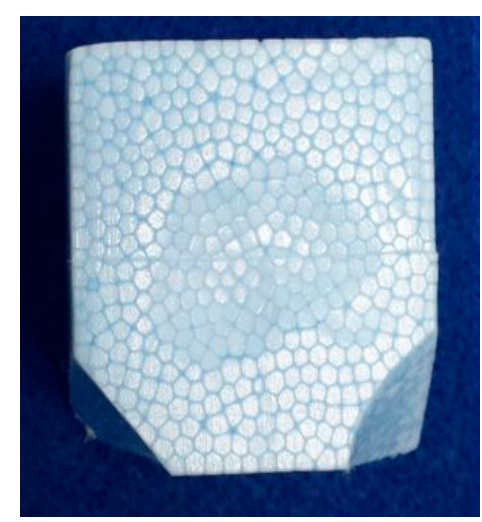

(a)

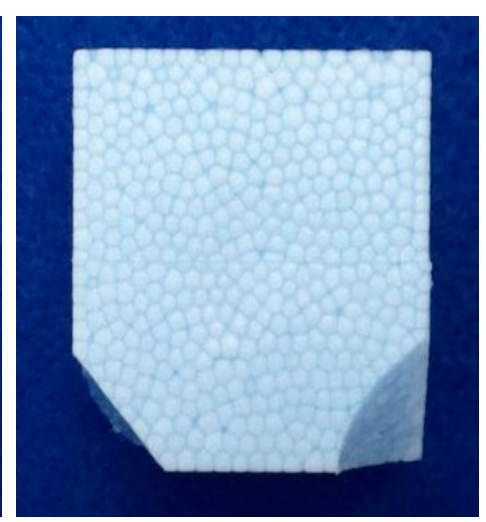

(b)

Figure 2 demonstrates the heating-responsive SME in poly(lactic acid) (PLA), which is biodegradable and has found a number of biomedical applications. Note, that here, the original shape is produced using $1.75 \mathrm{~mm}$ diameter PLA filament, which is one of most popular filament materials for 3D printing. Polyimide (PI) is featured by its high thermal stability. Figure 3 reveals that after being indented twice from its back side at room temperature (about $22{ }^{\circ} \mathrm{C}$ ), the PI tape from $3 \mathrm{M}$ is able to recover, but only slightly, when it is heated. Readers may refer to [7] for more examples of the SME in many engineering polymers and even ourselves (e.g., human hair and nail are indeed SMM). 
Figure 2. The SME in poly(lactic acid) (PLA). (a) original shape; (b) after deformation; and (c) after heating in hot water.

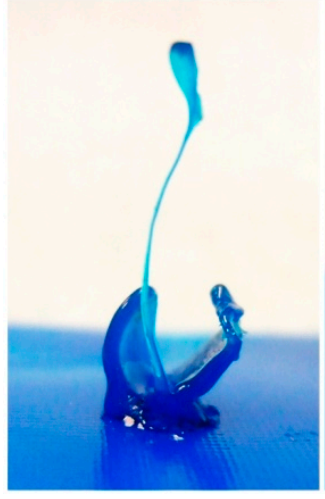

(a)

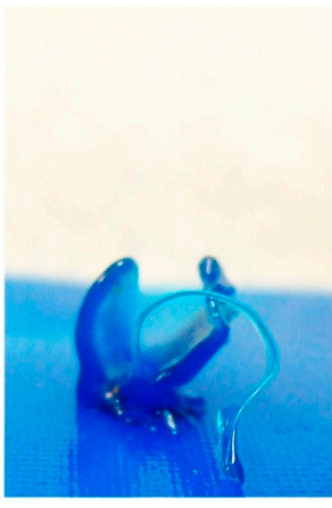

(b)

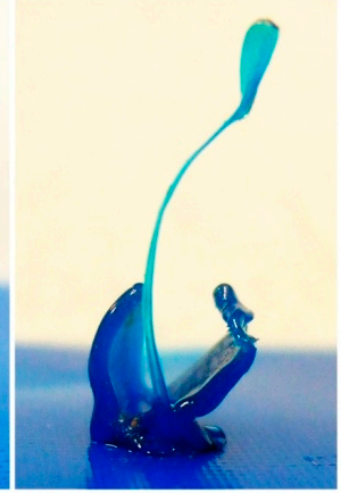

(c)

Figure 3. The heating-responsive SME in Polyimide (PI) tape (comparison of cross-sections of two indents right after indentation and in subsequent step-by-step heating to different temperatures).

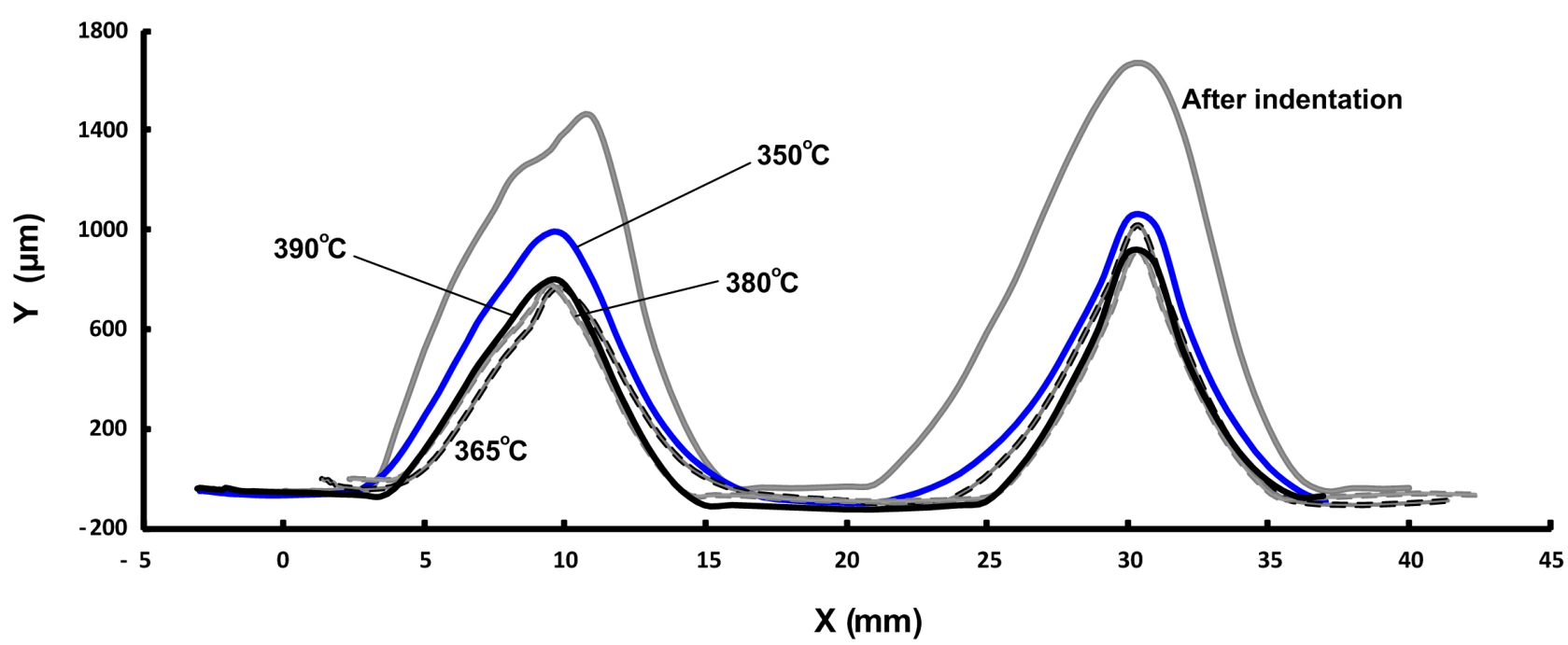

We have expected the SME in polymers to reshape product design in many ways for about one decade [10]. Recent progress has proven that this effect is indeed a generic feature of most polymers. Hence, we are now able to extend this effect into a far wider range of applications. Furthermore, a number of shape memory related new phenomena and techniques have been developed, so that the conventional SMT may be extended to advanced shape memory technology (ASMT), which mainly includes three parts, as follows:

- The techniques to enable the SME in conventional materials;

- The techniques to design/tailor the shape memory function of a material to meet the requirement(s) of a particular application;

- The techniques to optimize the shape memory performance. 
Although the ASMT is not limited to polymers, in this review we will only focus on polymeric materials. Typical recent applications in design, manufacturing and recycling, which form a full life cycle of products, will be presented to reveal the potentials of the ASMT.

Section 2 is about the basic working mechanisms of the SME and related technologies. Section 3 presents typical designs based on the ASMT. Section 4 briefly reviews the applications of the ASMT as a novel manufacturing approach. Recycling-based ASMT is addressed in Section 5. Major conclusions are summarized in Section 6.

\section{Working Mechanisms and Technologies}

There are a number of possible mechanisms to achieve the SME in materials. Some of them are specific and even application/size dependent, while some others are more generic and applicable in a range of materials and applications, so that they are basic working mechanisms.

In this section, the basic working mechanisms of the heating-responsive SME are discussed to reveal the fundamentals. According to [11], there are three basic types of working mechanisms for the heating induced shape recovery. They are listed below (refer to Figure 4).

Figure 4. Basic working mechanisms of the heating-responsive SME in polymeric materials. (I) Dual-state mechanism (DSM); (II) dual-component mechanism (DCM); and (III) partial-transition mechanism (PTM). (a) Original sample at low temperatures; (b) upon heating and compressing; (c) after cooling and constraint removal; and (d) after heating for shape recovery [11].

(I)

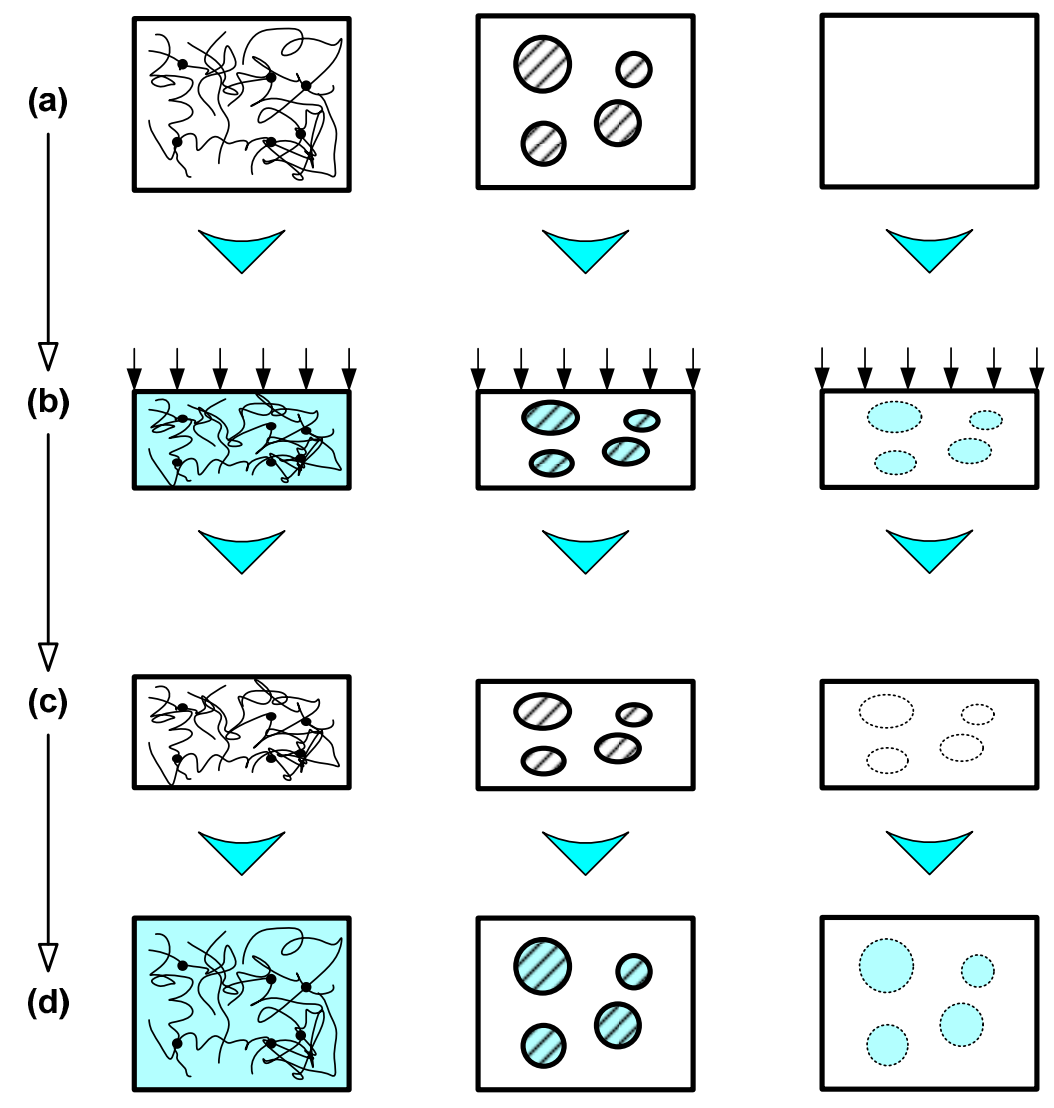


- Dual-state mechanism (DSM) (Figure 4I)

A typical example is to utilize the glass transition of polymers. Above $T_{\mathrm{g}}$, a polymer is in the rubbery state and soft. It may be easily deformed. Upon cooling to below $T_{\mathrm{g}}$, the polymer is in the glassy state and hard. After removal of the constraint, the deformed shape may be largely maintained. The original shape may be recovered upon heating to above $T_{\mathrm{g}}$ again. Here, the cross-link (either chemical or physical) serves as the element to store the elastic energy, which serves as the driving force for shape recovery in the later stage.

- Dual-component mechanism (DCM) (Figure 4II)

Here, two components may refer to hard and soft segments or matrix and inclusion. Hard segment or matrix should be elastic within the working temperature range of an application. On the other hand, the soft segment or inclusion becomes soft upon heating, so that the material is easier to deform at high temperatures. Same as that in DSM, after cooling and removal of the constraint, the deformed shape can be largely kept, until it is heated again to soften the soft segment or inclusion for shape recovery.

- Partial-transition mechanism (PTM) (Figure 4III)

Without the requirement of either cross-link or hard/soft segment or matrix/inclusion, upon heating to the middle of a transition, so that only part of a polymer is softened, we may deform it as a system of elastic sponge filled with soft inclusion. After cooling, the softened part becomes hard again so that shape recovery is effectively prevented. Only upon heating to re-soften the previously softened part results in shape recovery.

Both DSM and DCM are well-known within the SMP community, as most of previous research works and applications are based on them. PTM does not attract much attention in the past and it requires special care in implementation. In real practice, PTM may be applied together with DSM or DCM.

Traditionally, the first step to deform a material into a temporary shape is called the programming process, and the next step is called the shape recovery process. These two processes form a complete shape memory cycle.

It should be pointed out that both high recovery strain and high shape recovery ratio are special features of SMPs, but they are not always essential in engineering applications. For instance, a few percent of compression strain is good enough to induce wrinkling and in such an application, shape recovery is not required to be $100 \%$ [12-14].

Based on above working mechanisms, one can easily design his/her own shape memory material in a DIY manner.

Figure 5 reveals the SME in a shape memory hybrid (SMH) made of elastic sponge and wax, which are materials available in most supermarkets and have no SME as individuals. The process to prepare the hybrid is as following. After soaking in melted wax for a couple of times, the sponge is compressed at high temperatures above the melting point of wax. After cooling back to room temperature and then heating to melting temperature of wax again, the sponge-wax hybrid returns the original shape of the elastic sponge. Now a piece of SMH is ready. The melting temperature of wax determines the actual 
transition temperature of the SMH. Depending on the actual volume fraction of wax, the mechanical properties of the hybrid can be tailored (Figure 6).

Figure 5. The SME in sponge-wax hybrid. (a) Original shape; (b1) indented at high temperatures using a coin; (b2) cooling in air; (b3) removal of constraint; (c1-c3) upon heating using a hair dryer; and (d) after heating.
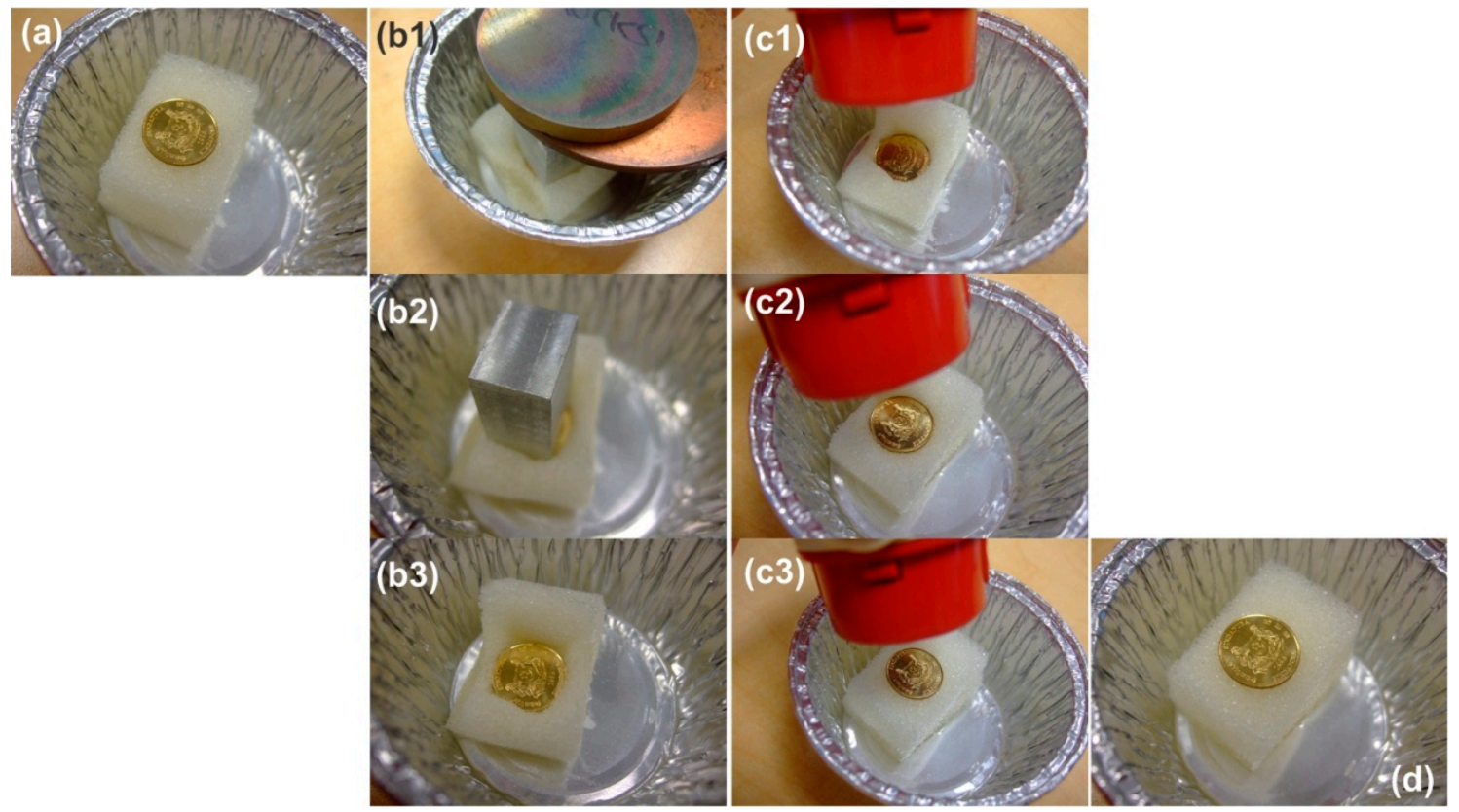

Figure 6. Engineering stress $v s$. engineering strain relationships of sponge, sponge-wax hybrid and wax in uniaxial compression.

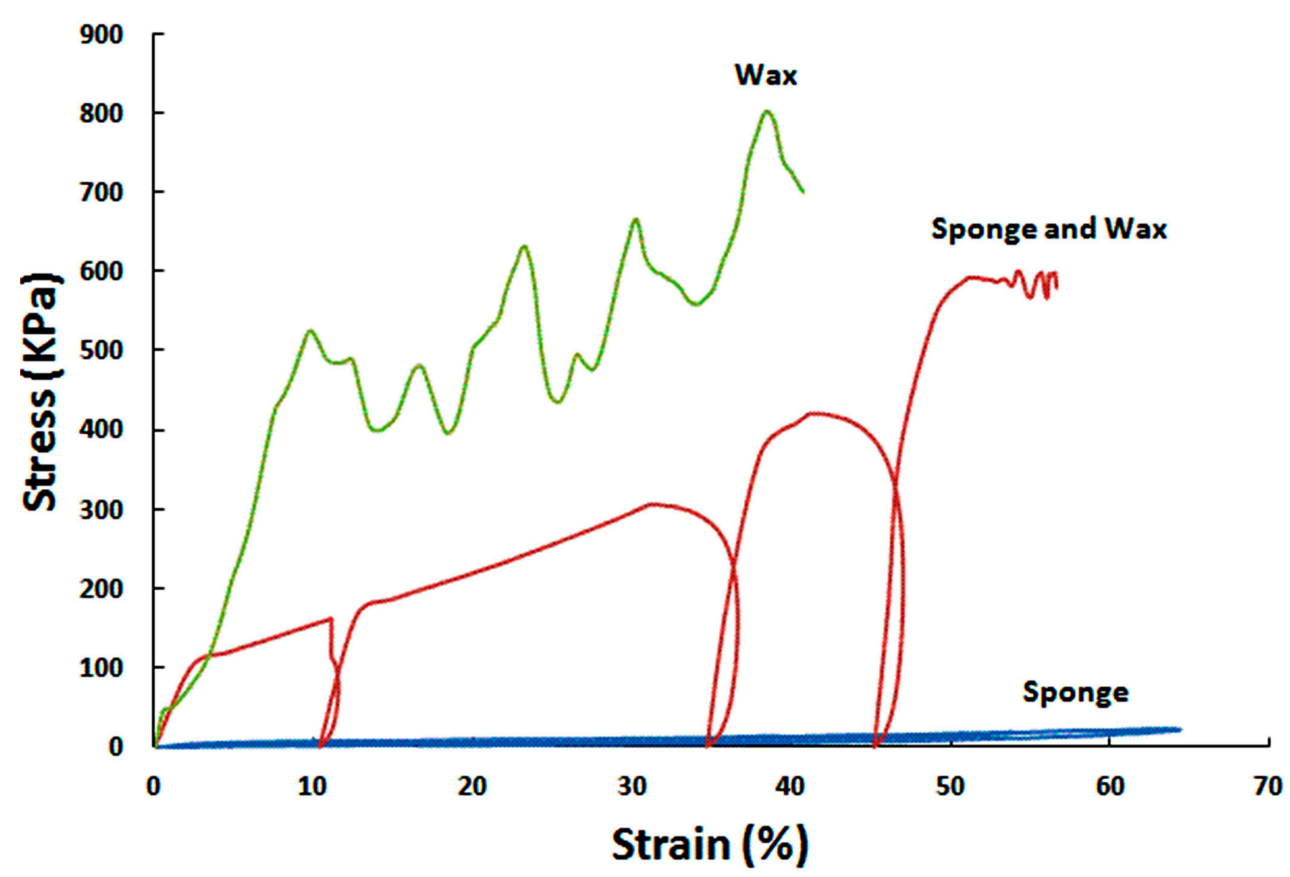

The change in microstructures in a typical heating-responsive shape memory cycle is illustrated in Figure 7 using a representative unit. Refer to Figure 8 for the corresponding strain and stress in this cycle. In all mechanisms presented in Figure 4, there are essentially two parts, namely the elastic part 
and the transition part (Figure 7a). Upon heating to high temperatures so that the transition part becomes soft, the material is stretched to a maximum strain of $\varepsilon_{\max }$ (Figure $7 \mathrm{~b}$ ). After cooling back, the transition part is hardened, and thus, after unloading, apart from a bit of elastic recovery, the deformed shape is largely maintained (Figure 7c). The residual strain $\varepsilon_{r}^{s}$ may decrease to $\varepsilon_{r}^{l}$ due to creeping (Figure 7d). Upon heating to soften the transition part again, the elastic energy stored in the elastic part is released, so that the residual strain is further reduced to $\varepsilon_{R}$ (Figure $7 \mathrm{e}$ ).

Figure 7. A representative unit to schematically illustrate full heating-responsive shape memory cycle.

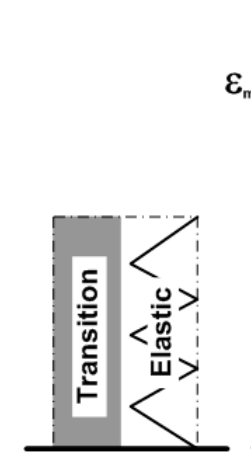

(a)

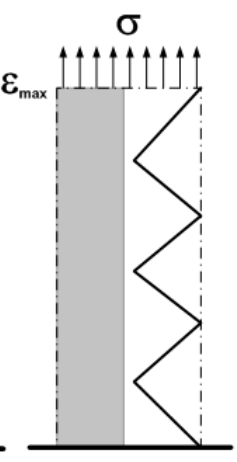

(b)

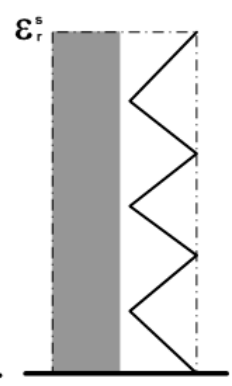

(c)

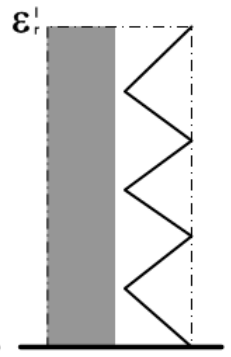

(d)

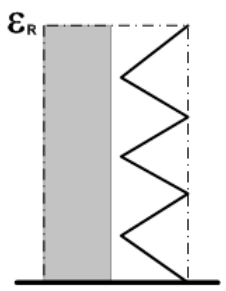

(e)

Figure 8. Illustration of the shape memory cycle in terms of stress vs. strain curve.

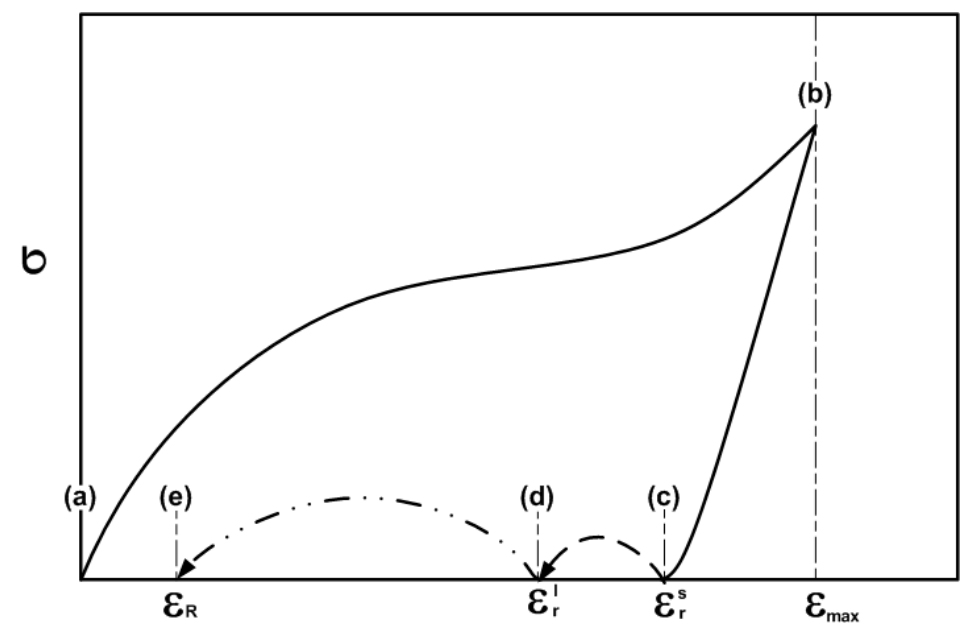

Hence, we may define the short-term shape fixity ratio $\left(R_{f}^{s}\right)$ as:

$$
R_{f}^{s}=\frac{\varepsilon_{r}^{s}}{\varepsilon_{\max }}
$$

the long term shape fixity ratio $\left(R_{f}^{l}\right)$ as:

$$
R_{f}^{l}=\frac{\varepsilon_{r}^{l}}{\varepsilon_{\max }}
$$

and the shape recovery ratio $\left(R_{r}\right)$ as: 


$$
R_{r}=\frac{\varepsilon_{r}^{l}-\varepsilon_{R}}{\varepsilon_{r}^{l}}
$$

According to above discussion, long term shape fixity ratio may be influenced by creeping in the transition part, while shape recovery ratio may be affected by relaxation in the elastic part.

For a given polymer, by means of tailoring the programming parameters, namely, programming temperature and programming strain, the performance of a polymer in recovery may be optimized [7,15]. On the other hand, in addition to trying different synthesis methods/parameters, based on the working mechanisms discussed above, one can design a hybrid with the required shape memory function(s). For instance, in addition to rubber-like SMH with the self-healing function, cooling-responsive, water-responsive, and pressure-responsive SMHs have been developed [7,16-18].

Solvent, which may function as a plasticizer, has been demonstrated to be able to adjust the transition temperature to achieve the chemo-responsive SME [19]. For hydrogels, water may be utilized to tailor the shape memory/change behavior [9,20,21]. Self-healing has been realized in different types of polymeric materials [22-24].

Combined with the PTM, a silicone-melting glue hybrid [24], which is highly elastic above and below its transition temperature (the melting temperature of melting glue) may be programmed at different temperatures within the transition temperature range during cooling. In the subsequent gradual heating process, shape recovery is observed in a step-by-step manner (Figure 9), which is a phenomenon known as the multiple-SME (triple-SME, if there is only one intermediate shape) [25,26]. Note that for a polymer with multiple transitions or a gradient transition temperature field, shape recovery is naturally in a step-by step manner [27-34]. Essentially, the multiple-SME is a common feature of polymers, even there is only one transition [35].

Figure 9. Multiple-SME in silicone-melting glue hybrid. (a,b) are two indents. Upon gradual heating (1-3), (a) almost disappears in step 2, while (b) only disappears in step 3.

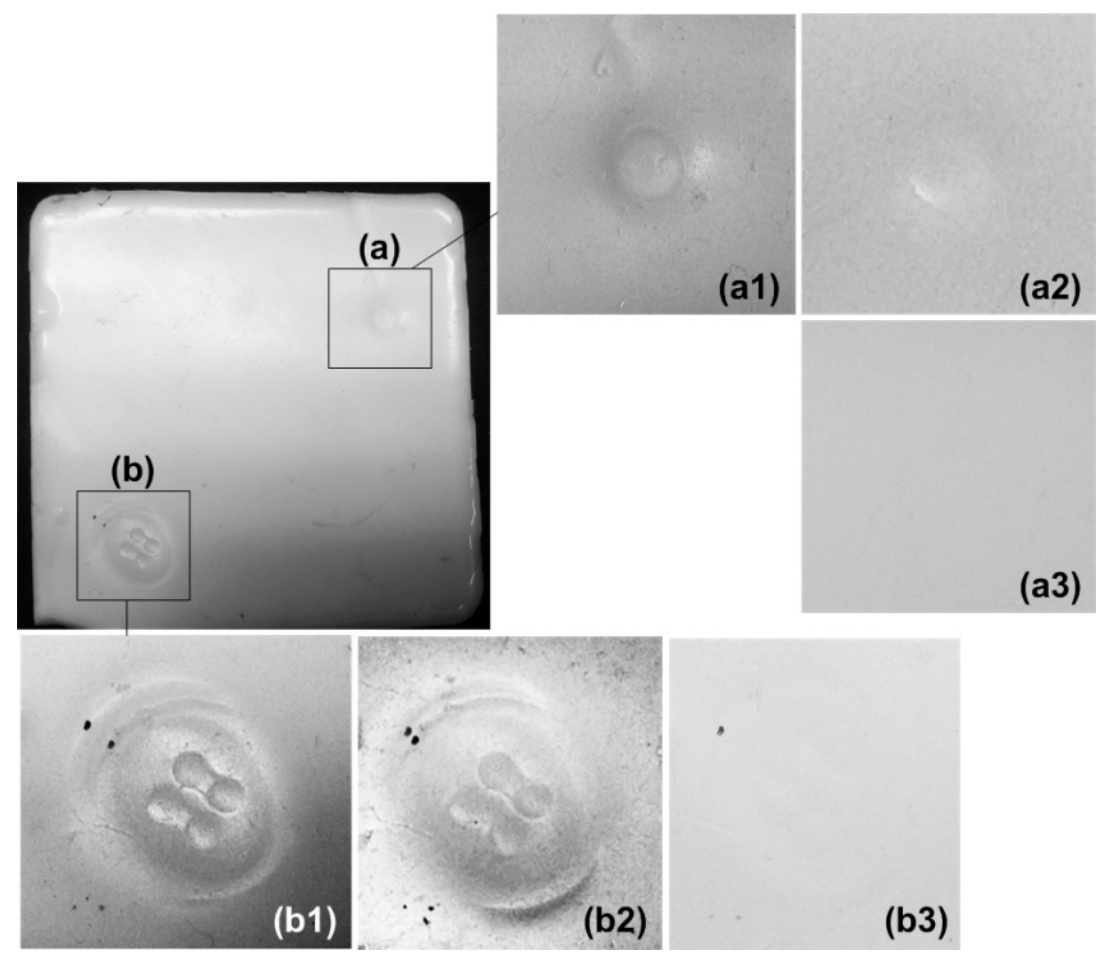


Many thermoplastic polymers, such as polycaprolactone (PCL), thermoplastic polyurethane (TPU) and melting glue are not traditionally considered to have the heating-responsive SME if based on the melting transition, unless they are cross-linked or blended [36-38]. In Figure 10a, a piece of PCL is impressed twice using the same side of a coin at two temperatures, one is above the melting temperature of PCL (top) and the other is room temperature (bottom), which is below the melting point. After heating in boiling water, which is well above the melting temperature of this PCL, the impression resulted at room temperature is largely recovered, while the impression produced at high temperatures is virtually unchanged. Similar shape memory phenomenon has been indentified in TPU and melting glue [7,11].

Figure 10. The SME in PCL. (a) After impression using a coin. Top: impressed above melting temperature; bottom: impressed at room temperature; and (b) after heating in boiling water.

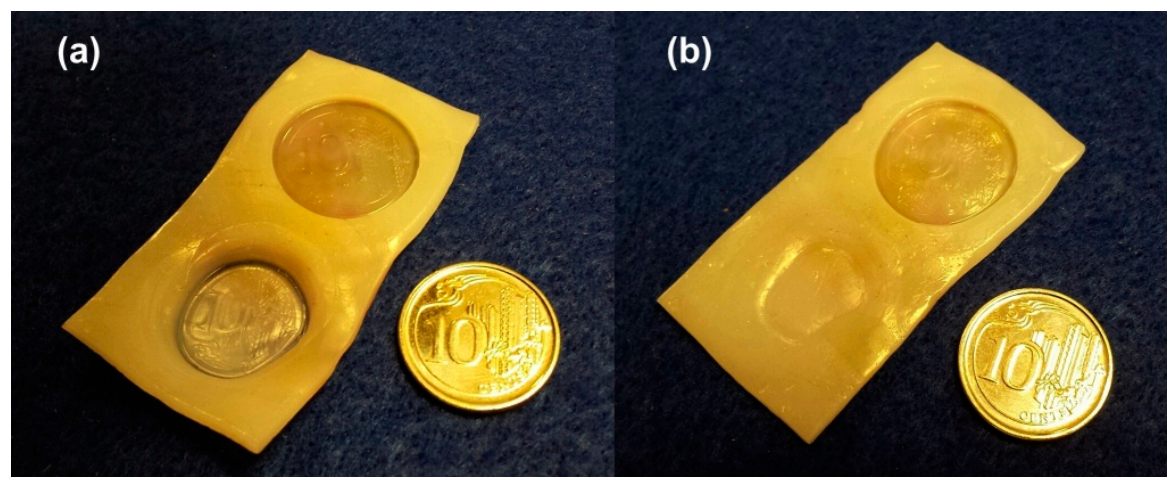

For transparent or translucent polymeric samples, such as poly(methyl methacrylate) (PMMA), polycarbonate (PC) and ethylene-vinyl acetate (EVA), traditional photoelastic technology may provide a convenient approach to investigate the detailed shape recovery process. As we can see in Figure 11, under normal light, it is difficult to identify the difference in the impressions before and after heating for shape recovery. But under polarized light, the difference becomes apparent.

Figure 11. Monitoring shape recovery in EVA, based on photo-elasticity. (a1,a2) before heating; (b1,b2) after heating the right half of sample in boiling water. (1): normal light; (2): polarized light.

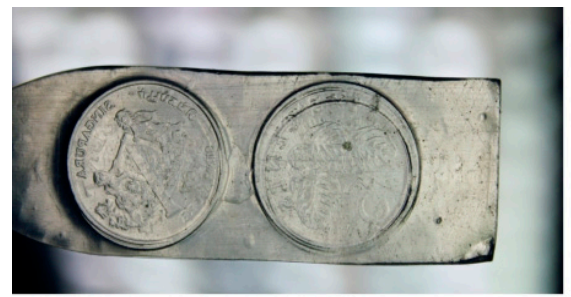

(a1) Before heating, normal light

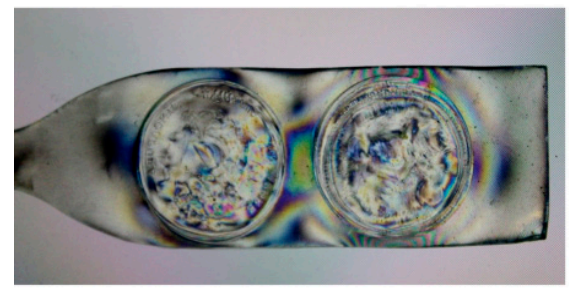

(a2) Before heating, polarized light

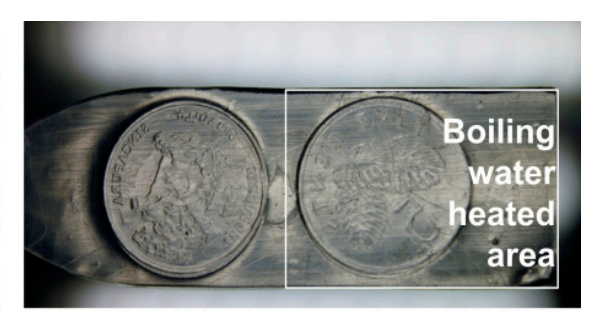

(b1) After heating, normal light

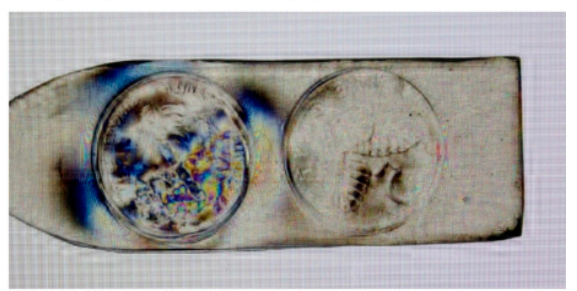

(b2) After heating, polarized light 


\section{Design}

The ASMT provides an additional design tool to achieve not only "The material is the machine" [39] for actuation as in traditional applications of SMMs [6,30,40-42], but also the material is an integrated sensing system to directly reveal what is detected [43-45].

Since there are many review papers about the actuation applications of SMPs (e.g., in [5,46-51]), herein, only two examples related to "4D printing" of biomedical devices for minimally invasive surgery are presented.

There are at least two different ways to define the so called 4D printing, which has one more dimension than $3 \mathrm{D}$ printing. This additional dimension may refer to the variation of material properties or the ability of shape/morphology switching in a piece of 3D printed structure. Although it has just been demonstrated that both can be achieved simultaneously using multiple nozzles in printing [52], here we limit our discuss to the very basic one, i.e., shape switching in homogeneously 3D printed structures. As SME is common in many polymeric materials, shape switching (4D) is essentially a generic feature of $3 \mathrm{D}$ printed polymeric devices/structures.

PLA is one of the most popular filaments used in $3 \mathrm{D}$ printing at present. It is also biodegradable and has been used for surgical staples. In Figure 12, the concept of self-tightening PLA staple, which is highly applicable in minimally invasive surgery, is demonstrated. Here, the staple is designed used Solidworks and then 3D printed by MakerBot Replicator II using $1.75 \mathrm{~mm}$ diameter PLA filament.

Figure 12. 3D printed PLA staple with self-tightening function. (a) The SME in staple; and (b) demonstration of tightening function, before and after heating for shape recovery.

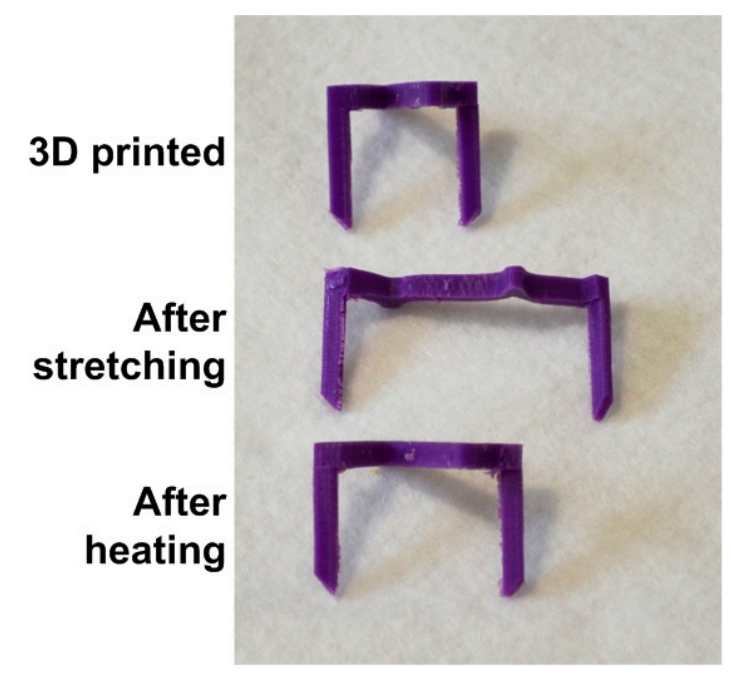

(a)

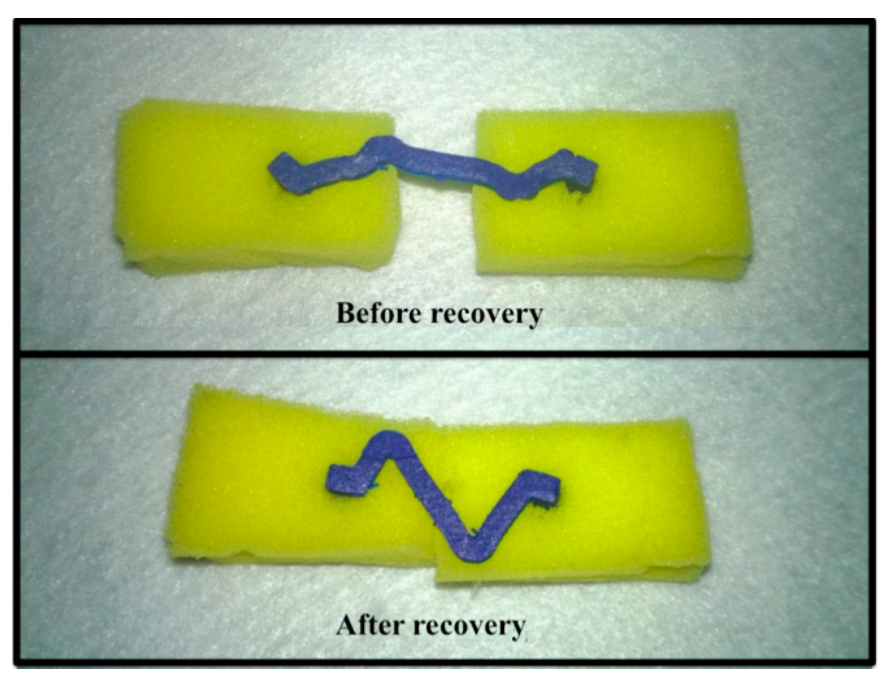

(b)

Although surgical removal of liver tumors offers the best chance for a cure, more than $70 \%$ of the liver cancer patients are inoperable and are treated with a palliative embolization, like transcather arterial chemoembolization (TACE) and selective internal radiation therapy (SIRT) for liver tumor treatment. Embolization is a minimally invasive procedure that selectively occludes blood vessels by means of introduction of embolic agents. Currently, the embolic agents used are generally non-biodegradable and, thus, result in permanent vessel occlusion. Specially designed and 3D printed PLA spiral springs (such as the one shown in Figure $13 \mathrm{a}-\mathrm{c}$ ) can be straightened and then heated for shape recovery. 
In the straightened shape, they can be stored inside a catheter and then delivered to the required position before deployment.

Since the SME implies the ability of a SMM to respond to a right stimulus, such as heat, via shape/morphology change, based on the observed shape/morphology difference, if any, we can tell whether a piece of polymer has ever been exposed to the right stimulus. Consequently, the polymer may be used as a piece of integrated sensor, in which the result may be directly observed by naked eyes. After integrating with other mature techniques, we can further improve the design of such sensors in many ways.

Figure 13. 3D printed springs for temporary endovascular embolization in interventional radiology. (a) Straightened shape (top) and then heated for shape recovery (middle to bottom); $(\mathbf{b}, \mathbf{c})$ a more complicated version. (b) 3D view of concept; (c) 3D printed prototype.

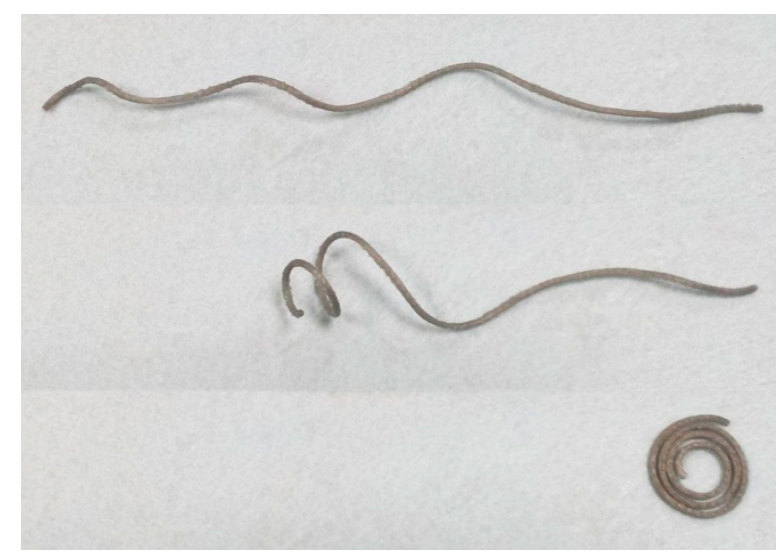

(a)

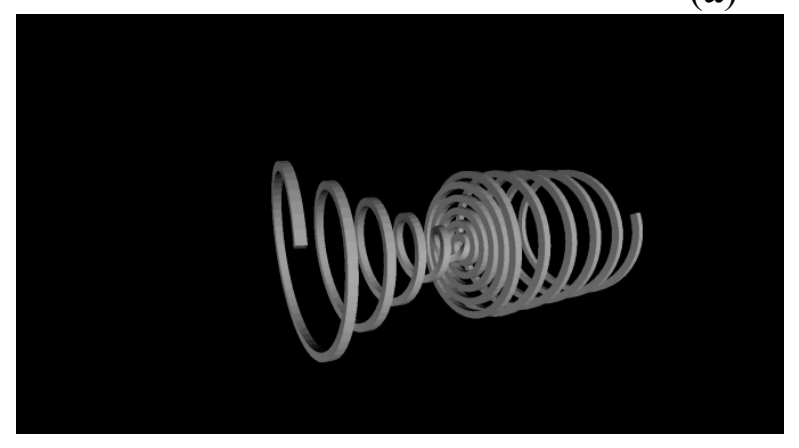

(b)

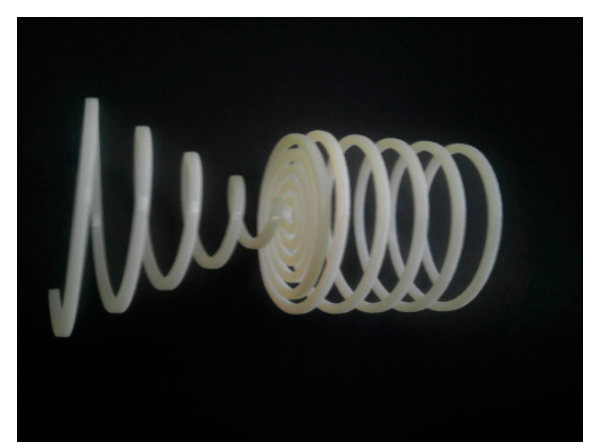

(c)

Figure 14a shows a piece of PLA card, which is 3D printed using Makerbot: Replicator II and has a word of SMT atop. In the next step, $\mathrm{S}$ is impressed at above the $T_{\mathrm{g}}$ of PLA, so that it becomes difficult to recognize (Figure 14b). After heating to above the $T_{\mathrm{g}}, \mathrm{S}$ recovers (Figure 14c). The main advantage of customized feature in 3D printing is maintained, while the major disadvantage of time consuming and thus high cost is minimized by only printing a very thin layered 3D structure. A smaller sized version of such a card may be applied as a customized anti-heating transfer sticker for anti-counterfeit purpose.

A similar idea may be applied in quick response $(\mathrm{QR})$ code to remarkably enhance the level of security [44,53-55]. In Figure 15, QR code $(10 \times 10 \mathrm{~mm})$ is printed on a piece of paper and then stuck to the backside of a commercial 75 line/inch (LPI) lenticular lens (made of polyethylene terephthalate, PET, with a $T_{\mathrm{g}}$ about $65^{\circ} \mathrm{C}$ ) and then the front side of the lens is flattened at $100{ }^{\circ} \mathrm{C}$ so that the encoded 
message can be easily recognized using a mobile phone. However, if it is heated to above its $T_{\mathrm{g}}$ again, the lenticular lens recovers its original shape, and, thus, the code becomes unreadable.

One step further is to implement the so called multiple-SME to achieve step-by-step recovery with only one-step in programming. As revealed in Figure 16a, a piece of specially designed lenticular lens (made of $4 \mathrm{~mm}$ thick polystyrene (PS), with a $T_{\mathrm{g}}$ about $70{ }^{\circ} \mathrm{C}$ bought from Cornerstone Research Group, USA) is able to be used as a temperature label to record heating temperature by means of permanent showing the backside lines on its front side surface in the middle part as indicated. Since these lines appear from the right towards the left upon gradual heating, after proper calibration, a resolution of better than $0.5{ }^{\circ} \mathrm{C}$ can be realized. Here, a stainless steel (SUS 304) mold with a variable radius in individual indents is used (Figure 16b, in which only two radii are indicated), so that after impression to a prescribed depth atop PS plate at $100{ }^{\circ} \mathrm{C}$ and then cooling down, a non-uniform lenticular lens is produced in the middle of PS plate. At a certain view angle, the backside lines become visible only upon heating. The radii of the lenticular lens are carefully calculated to ensure the backside lines appear at different temperatures. Essentially, such a temperature label is low cost. If a low transition temperature polymer is used, it may be applied in cold chain logistics to monitor whether overheating has ever occurred in an individual package of food or medicine and to reveal how high the actual overheating temperature is.

Figure 14. Change of surface morphology in a 3D printed PLA card with "SMT" atop. Left: 3D view; right: top view (3D scanned). (a) As printed; (b) after "S" is impressed; and (c) after heating for shape recovery.
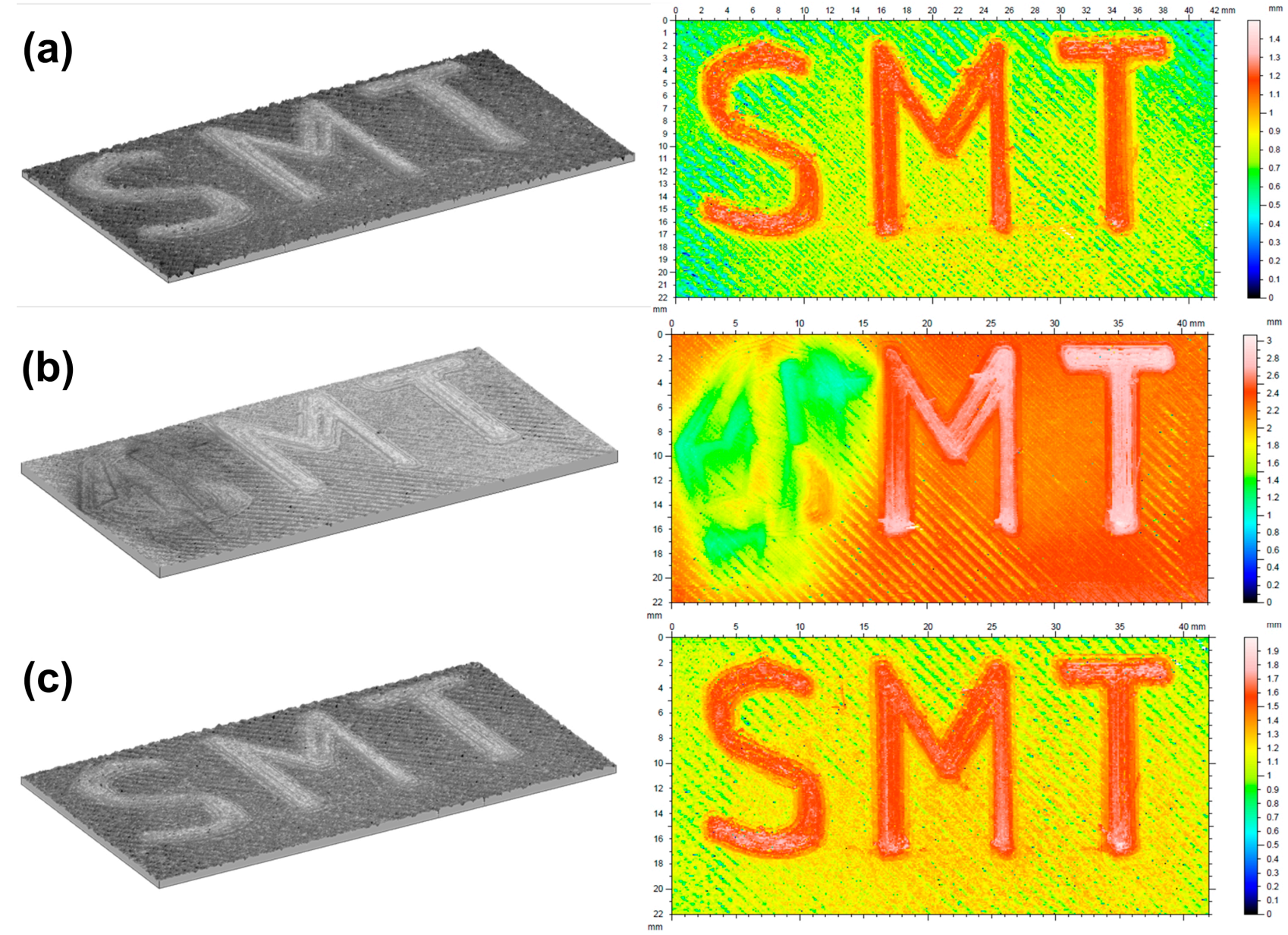
Figure 15. Anti-heating transfer quick response (QR) code. (a) Before heating; and (b) after heating.

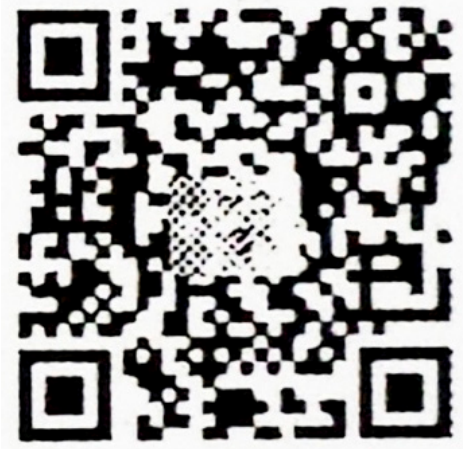

(a)

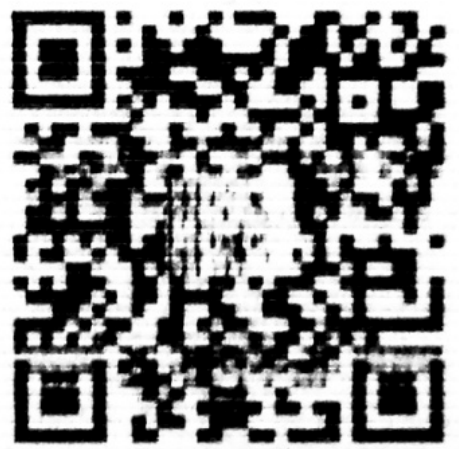

(b)

Figure 16. Polymeric temperature label upon heating (a) and cross-section of stainless steel mold for impression (b).

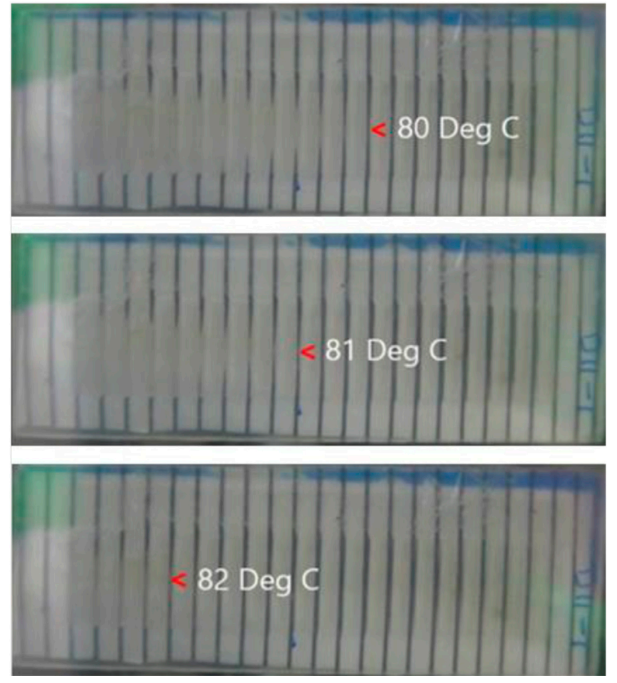

(a)
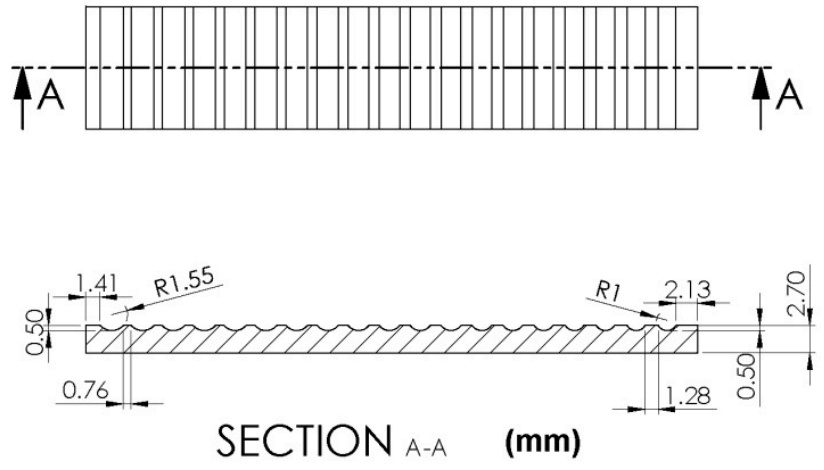

(b)

Structural color is a result of nano sized structural features $[13,14,56]$. Instead of based on the techniques, such as self-assembly, nano-imprinting is more straightforward for massive fabrication of well defined nano-structures in a roll to roll manner [57]. In Figure 17, part of a thin polycarbonate (PC) film is with nano-imprinted features so that it has rainbow like color. Upon heating part of the film using a lighter, the rainbow colored area shrinks as the result of heating induced SME, which causes the nano-structure to disappear.

Figure 17. Heating to partial remove structural color in nano-imprinted PC film.

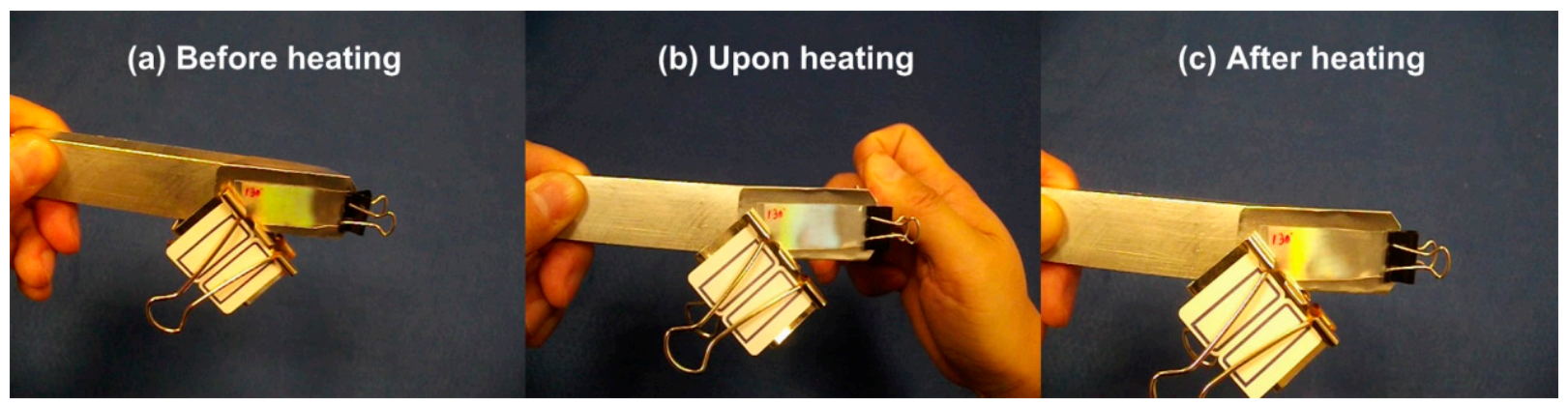


The temperature memory effect (TME) has been proved to be an intrinsic feature of polymers, which may appear in two different ways under two situations of recovery, i.e., maximum stress in constrained recovery and almost full shape recovery or the maximum shape recovery ratio in free recovery $[25,35,58]$. In fact, the TME and multiple-SME are related and thus both effects may be combined together into a design.

Different from that in Figure 16, in which shape recovery propagates from one side towards the other side, shape change may occur over the same area for more than one time upon gradual heating.

As demonstrated in Figure 18, after being properly programmed, the impression atop a piece of PMMA is able to switch from one side of coin (mirror image) to the other side of coin (mirror image) when it is heated at $120^{\circ} \mathrm{C}$. Upon further heating, the second impression gradually fades away. Such a feature is achieved by impressing twice using two sides of a coin at $135{ }^{\circ} \mathrm{C}$ and $115{ }^{\circ} \mathrm{C}$, respectively, over the same location. An alternative is to have the second image emerge within the first image and then gradually disappear together [8] or to let the impression fade away in a step-by-step manner [29].

Figure 18. Evolution of surface morphology upon heating in PMMA. Top row: optical image; bottom row: 3-D surface scanning. (a) After programming; (b) after heating to $120{ }^{\circ} \mathrm{C}$; (c) after heating to $140{ }^{\circ} \mathrm{C}$; and (d) after heating to $160{ }^{\circ} \mathrm{C}$. Reproduced with permission from Elsevier, 2014 [59].

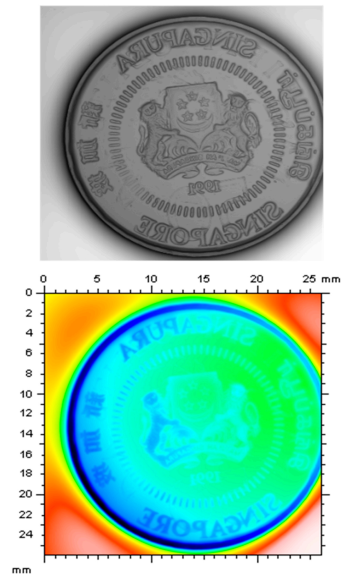

(a)

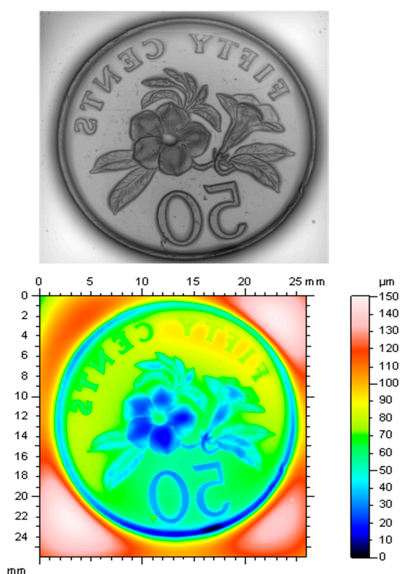

(b) $120^{\circ} \mathrm{C}$

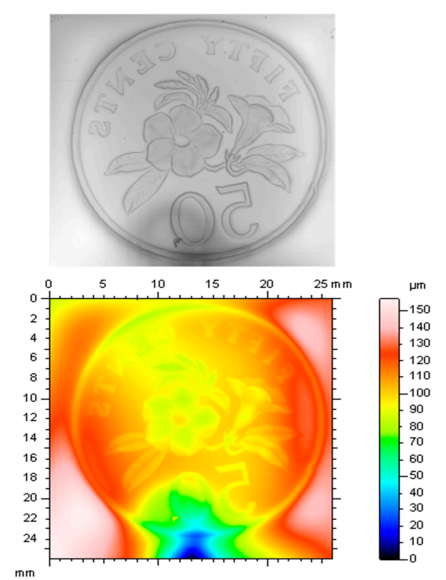

(c) $140^{\circ} \mathrm{C}$

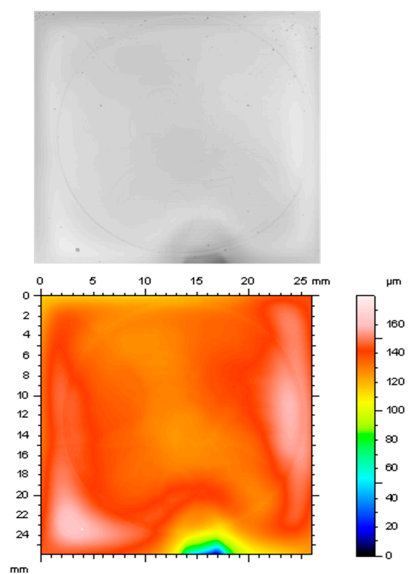

(d) $160^{\circ} \mathrm{C}$

\section{Fabrication}

The SME may be used as a novel fabrication technique. Reusable mandrel/inner mold [60], self-assembly/folding to form 4D structures [52,61,62], and active assembly [41] are some typical applications.

Wrinkling atop a polymeric substrate with/without deliberated pre-deformation can result in various types of surface patterns $[63,64]$. Some examples are presented in Figure 19 to reveal the variety of the wrinkle patterns. In comparison with the traditional fabrication methods, in which, most likely, pre-deformation in the elastic substrate needs to be carefully maintained during coating of a stiffer layer (e.g., [65-67]), the SME in polymers provides great flexibility for a far wider range of variety of wrinkle patterns. 
Figure 19. Wrinkling atop polymeric substrate. Reproduced with permission from Elsevier, 2013 [30].

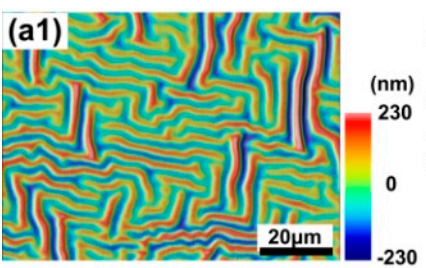

(a) Labyrinth-shaped wrinkles

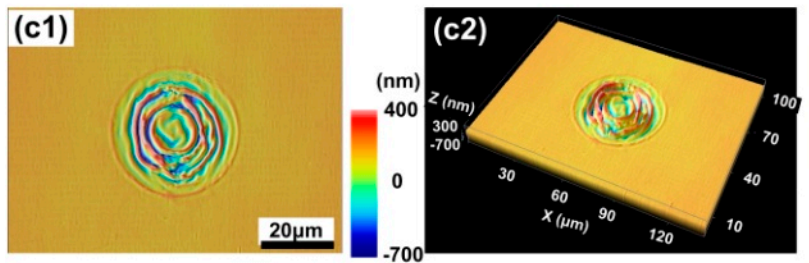

(c) Ring-shaped wrinkles

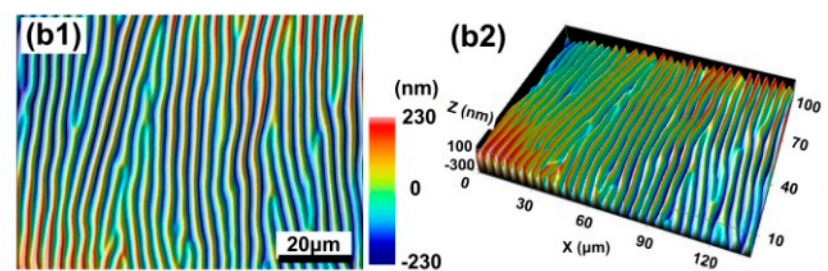

(b) Stripe-shaped wrinkles

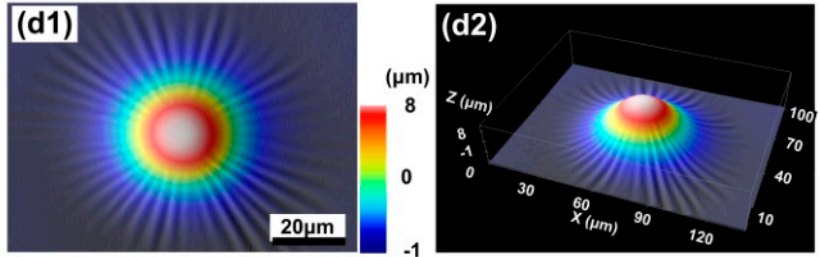

(d) Radial-shaped wrinkles
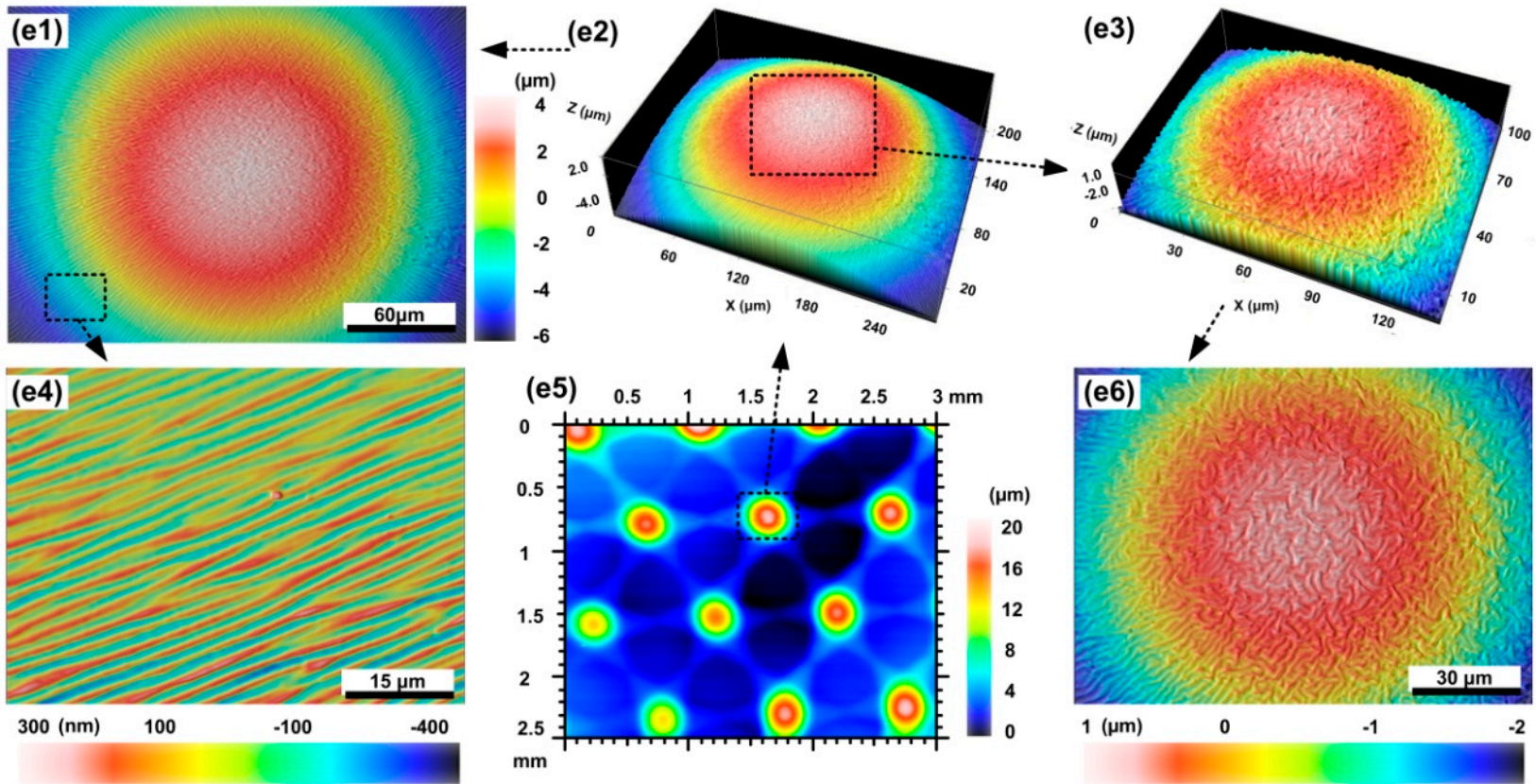

(e) Protrusion/wrinkle array

3D microlens array (or insect eye) not only provides a larger angle of view, but also is capable to capture 3D images. It has great potential in encapsulated endoscope and sub-millimeter sized endoscope to provide 3D images for surgeons in minimally invasive surgery. As compared with the conventional methods (e.g., in [68]), the SME provides convenience in fabricating small sized 3D microlens array. An example is presented in Figure 20, in which the phenomenon of stress-enhance swelling of PMMA upon immersion into ethanol [69] is combined with the heating-responsive SME to produce 3D microlens array. For such a lens array, focusing is not an issue anymore, as it has the feature of "Shoot first, focus later". 
Figure 20. Three-dimensional microlens array. (a) Three-dimensional scanning of profile; (b) top view; and (c,d) two different views at two different locations. Reproduced with permission from Taylor \& Francis, 2014 [42].

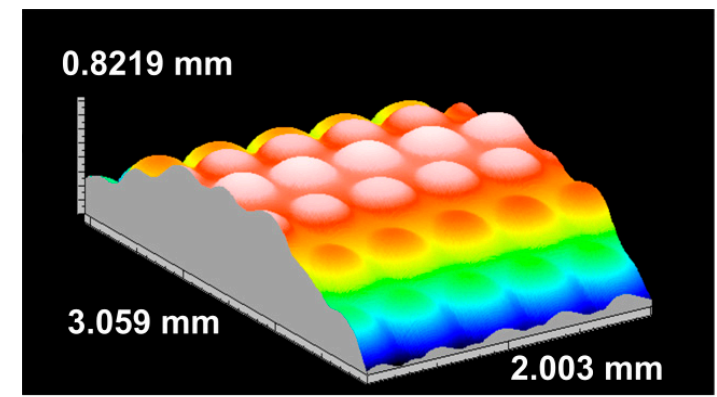

(a)

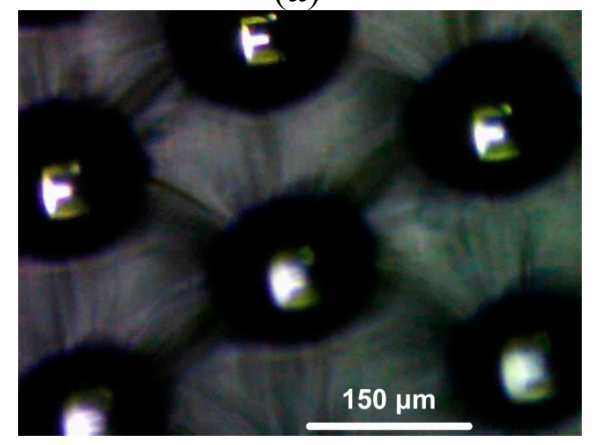

(c)

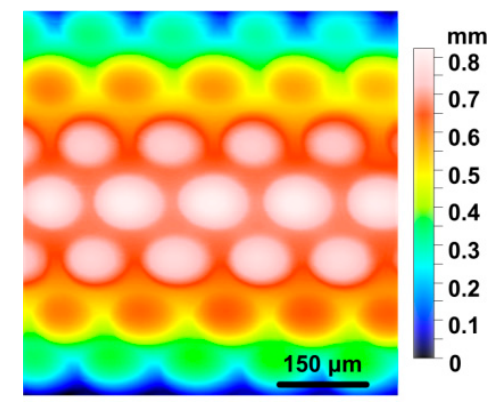

(b)

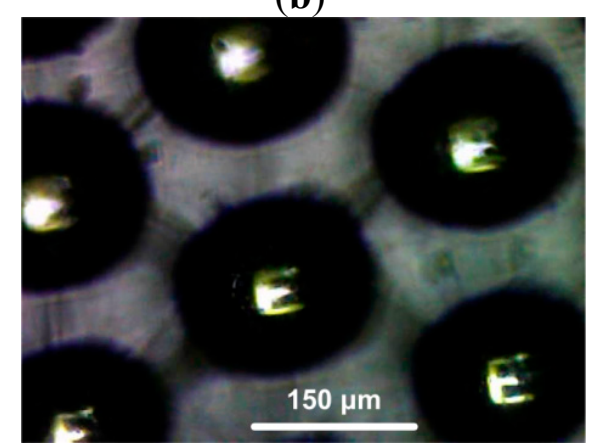

(d)

\section{Recycling}

For those obsolete electrical devices, recycling becomes an issue in order for environment protection. Disassembly is required in order to recycle different parts with high efficiency. The SME based disassembly, i.e., active disassembly [70-73], provides an alternative to replace manual disassembly. The multiple-SME of engineering polymers, such as PMMA and acrylonitrile butadiene styrene (ABS)/PC, enables us for programmed active disassembly [41,74]. As shown in Figure 21, after programming, the ABS/PC box disassembles in a step-by-step manner upon gradual heating.

At the material level, instead of decomposing polymers into monomer, which is complicate and difficult to be massively implemented, a special type of recyclable thermo-set polymer has been developed for easy recycling [75]. Very recently, we found that some hydrogels may be used to achieve active disassembly at sub-component level. Given the excellent heating and water/moisture-responsive SME in hydrogels [9], small hydrogel pieces may be compressed into a required shape with reasonable strength (Figure 22a). When it is required, by means of wetting (or heating, or a combination of both) the hydrogel component is able to disassemble into original small pieces (Figure 22b,c). After drying, these pieces are ready to be reused again (Figure 22d).

Figure 23 reveals the disassembly process in the first $280 \mathrm{~s}$, in which boiling water is used to trigger the disassembly. 
Figure 21. Programmed active disassembly of ABS/PC (used for Nokia NK-E51) box. (a) Assembled box; (b-h) upon gradual heating to different temperatures for a certain period of time; and (i) fully disassembled components A and B.
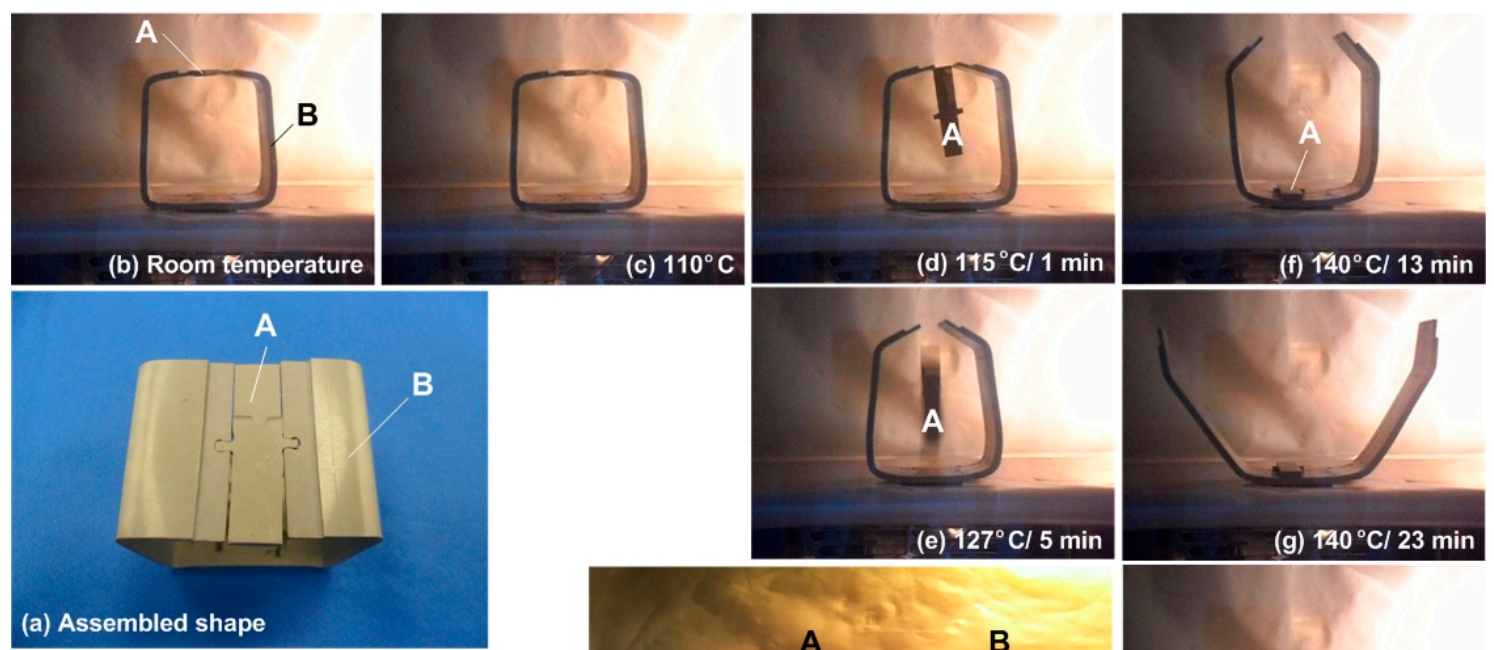

(a) Assembled shape
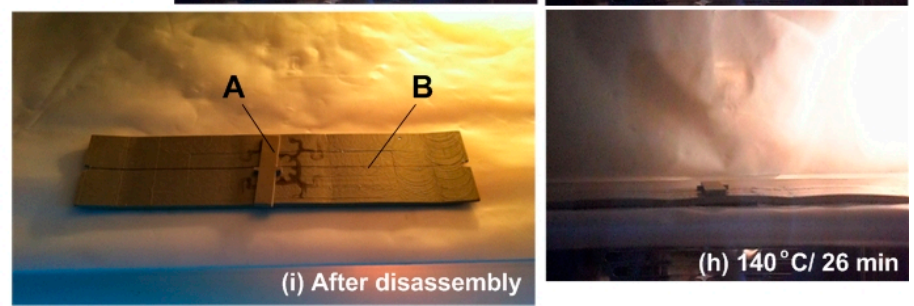

Figure 22. Disassembly upon wetting by hot water. (a) Assembled shape; (b,c) disassembly process; and (d) after drying.

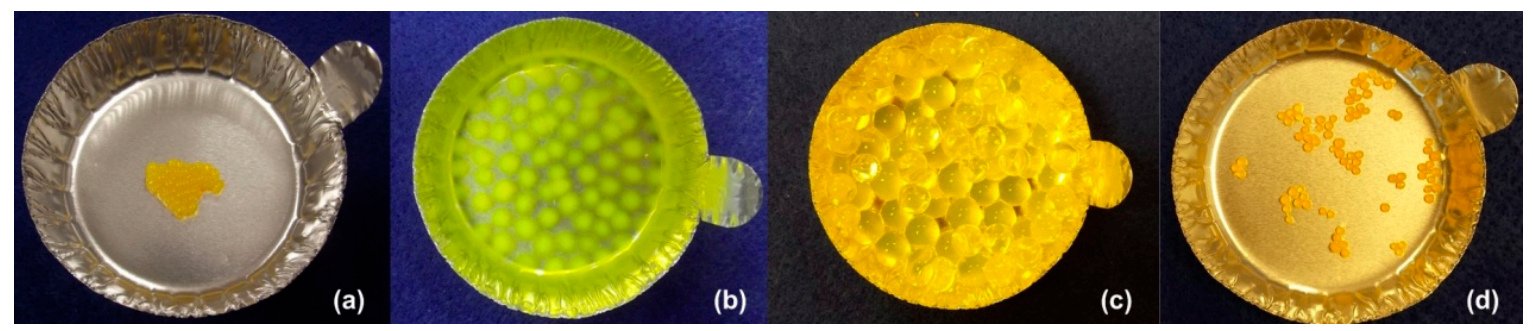

Figure 23. Snapshot of the disassembly process in the first $280 \mathrm{~s}$.

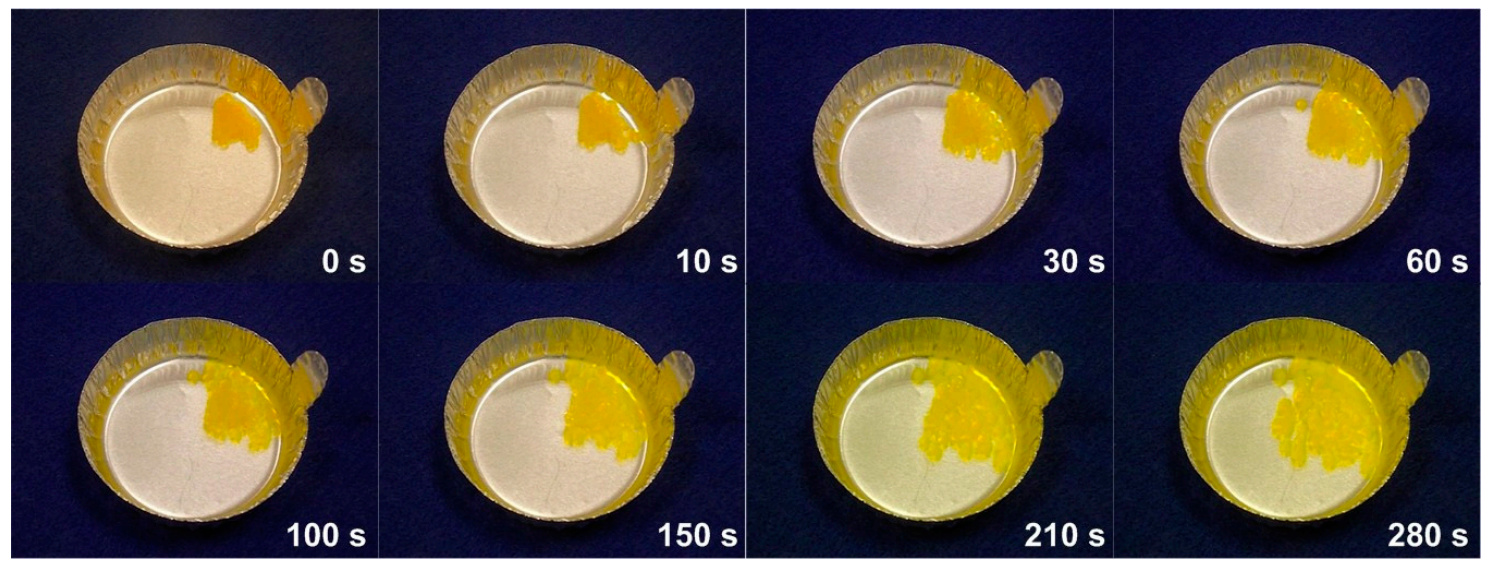




\section{Conclusions}

In addition to addressing the basic working mechanisms for the SME in polymeric materials and recent development in various new shape memory phenomena, this paper reviews the recent progress in the ASMT, which is an extension of the SMT and covers a range of techniques, including those to enable the SME in conventional materials, to design/tailor the shape memory function of a material to meet the requirement(s) of a particular application, and to optimize the shape memory performance. It is demonstrated the ASMT is easier to be accessed and implemented in real applications even by non-professionals in a DIY manner. As illustrated by some example applications, including those integrated with some well-known techniques (such as 3D printing, QR code, lenticular lens) and phenomena (e.g., wrinkling and stress-enhanced swelling effect), we may conclude that the ASMT has a great potential to reshape the whole life cycle of products, from design and manufacturing to recycling.

\section{Acknowledgments}

Chunyang Chen, Tiong Choon Koh, Xiaocong Lin, Hsi-chung Na, Phei Chieh Tan, Yu Long Tian, Eugene Jun Hao Yeo, Ye Zhou helped to conduct some of the experiments reported here.

\section{Author Contributions}

All authors have contribution to the proposed new concepts reported above. Wei Min Huang prepared the manuscript.

\section{Conflicts of Interest}

The authors declare no conflict of interest.

\section{References}

1. Otsuka, K.; Wayman, C.M. Shape Memory Materials; Cambridge University Press: Cambridge, UK, 1998.

2. Huang, W.M.; Ding, Z.; Wang, C.C.; Wei, J.; Zhao, Y.; Purnawali, H. Shape memory materials. Mater. Today 2010, 13, 54-61.

3. Wei, Z.G.; Sandström, R.; Miyazaki, S. Shape memory materials and hybrid composites for smart systems: Part II Shape-memory hybrid composites. J. Mater. Sci. 1998, 33, 3763-3783.

4. Wei, Z.G.; Sandstrom, R.; Miyazaki, S. Shape-memory materials and hybrid composites for smart systems: Part I Shape-memory materials. J. Mater. Sci. 1998, 33, 3743-3762.

5. Behl, M.; Lendlein, A. Shape-Memory Polymers; Springer-Verlag: Berlin, Germany, 2010.

6. Sun, L.; Huang, W.M.; Ding, Z.; Zhao, Y.; Wang, C.C.; Purnawali, H.; Tang, C. Stimulus-responsive shape memory materials: A review. Mater. Des. 2012, 33, 577-640.

7. Huang, W.M.; Zhao, Y.; Wang, C.C.; Ding, Z.; Purnawali, H.; Tang, C.; Zhang, J.L. Thermo/chemo-responsive shape memory effect in polymers: A sketch of working mechanisms, fundamentals and optimization. J. Polym. Res. 2012, 19, doi:10.1007/s10965-012-9952-z. 
8. Wu, X.L.; Huang, W.M.; Tan, H.X. Characterization of shape recovery via creeping and shape memory effect in ether-vinyl acetate copolymer (EVA). J. Polym. Res. 2013, 20, 1-11.

9. Zhang, J.L.; Huang, W.M.; Lu, H.B.; Sun, L. Thermo-/chemo-responsive shape memory/change effect in a hydrogel and its composites. Mater. Des. 2014, 53, 1077-1088.

10. Toensmeier, P.A. Shape memory polymers reshape product design. Plast. Eng. 2005, 61, 10-11.

11. Wu, X.; Huang, W.M.; Zhao, Y.; Ding, Z.; Tang, C.; Zhang, J. Mechanisms of the shape memory effect in polymeric materials. Polymers 2013, 5, 1169-1202.

12. Zhao, Y.; Huang, W.M.; Fu, Y.Q. Formation of micro/nano-scale wrinkling patterns atop shape memory polymers. J. Micromech. Microeng. 2011, 21, doi:10.1088/0960-1317/21/6/067007.

13. Li, J.J.; An, Y.H.; Huang, R.; Jiang, H.Q.; Xie, T. Unique aspects of a shape memory polymer as the substrate for surface wrinkling. ACS Appl. Mater. Interfaces 2012, 4, 598-603.

14. Xie, T.; Xiao, X.C.; Li, J.J.; Wang, R.M. Encoding localized strain history through wrinkle based structural colors. Adv. Mater. 2010, 22, 4390-4394.

15. Sun, L.; Huang, W.M.; Wang, C.C.; Zhao, Y.; Ding, Z.; Purnawali, H. Optimization of the shape memory effect in shape memory polymers. J. Polym. Sci. A Polym. Chem. 2011, 49, 3574-3581.

16. Wang, C.C.; Huang, W.M.; Ding, Z.; Zhao, Y.; Purnawali, H. Cooling-/water-responsive shape memory hybrids. Compos. Sci. Technol. 2012, 72, 1178-1182.

17. Fan, K.; Huang, W.M.; Wang, C.C.; Ding, Z.; Zhao, Y.; Purnawali, H.; Liew, K.C.; Zheng, L.X. Water-responsive shape memory hybrid: Design concept and demonstration. Express Polym. Lett. 2011, 5, 409-416.

18. Wang, C.C.; Ding, Z.; Purnawali, H.; Huang, W.M.; Fan, H.; Sun, L. Repeated instant self-healing shape memory composites. J. Mater. Eng. Perform. 2012, 21, 2663-2669.

19. Yang, B.; Huang, W.M.; Li, C.; Li, L. Effects of moisture on the thermomechanical properties of a polyurethane shape memory polymer. Polymer 2006, 47, 1348-1356.

20. Itagaki, H.; Kurokawa, T.; Furukawa, H.; Nakajima, T.; Katsumoto, Y.; Gong, J.P. Water-induced brittle-ductile transition of double network hydrogels. Macromolecules 2010, 43, 9495-9500.

21. Wang, Q.; Hou, R.X.; Cheng, Y.J.; Fu, J. Super-tough double-network hydrogels reinforced by covalently compositing with silica-nanoparticles. Soft Matter 2012, 8, 6048-6056.

22. Luo, X.F.; Mather, P.T. Shape memory assisted self-healing coating. ACS Macro Lett. 2013, 2, $152-156$.

23. Sun, T.L.; Kurokawa, T.; Kuroda, S.; Bin Ihsan, A.; Akasaki, T.; Sato, K.; Haque, M.A.; Nakajima, T.; Gong, J.P. Physical hydrogels composed of polyampholytes demonstrate high toughness and viscoelasticity. Nat. Mater. 2013, 12, 932-937.

24. Wang, C.C.; Huang, W.M.; Ding, Z.; Zhao, Y.; Purnawali, H.; Zheng, L.X.; Fan, H.; He, C.B. Rubber-like shape memory polymeric materials with repeatable thermal-assisted healing function. Smart Mater. Struct. 2012, 21, doi:10.1088/0964-1726/21/11/115010.

25. Xie, T. Tunable polymer multi-shape memory effect. Nature 2010, 464, 267-270.

26. Bellin, I.; Kelch, S.; Langer, R.; Lendlein, A. Polymeric triple-shape materials. Proc. Natl. Acad. Sci. USA 2006, 103, 18043-18047.

27. Bellin, I.; Kelch, S.; Lendlein, A. Dual-shape properties of triple-shape polymer networks with crystallizable network segments and grafted side chains. J. Mater. Chem. 2007, 17, 2885-2891. 
28. Behl, M.; Bellin, I.; Kelch, S.; Wagermaier, W.; Lendlein, A. One-step process for creating triple-shape capability of AB polymer networks. Adv. Funct. Mater. 2009, 19, 102-108.

29. Wu, X.L.; Huang, W.M.; Seow, Z.G.; Chin, W.S.; Yang, W.G.; Sun, K.Y. Two-step shape recovery in heating-responsive shape memory polytetrafluoroethylene and its thermally assisted self-healing. Smart Mater. Struct. 2013, 22, doi:10.1088/0964-1726/22/12/125023.

30. Huang, W.M.; Song, C.L.; Fu, Y.Q.; Wang, C.C.; Zhao, Y.; Purnawali, H.; Lu, H.B.; Tang, C.; Ding, Z.; Zhang, J.L. Shaping tissue with shape memory materials. Adv. Drug Deliver. Rev. 2013, 65, 515-535.

31. DiOrio, A.M.; Luo, X.F.; Lee, K.M.; Mather, P.T. A functionally graded shape memory polymer. Soft Matter 2011, 7, 68-74.

32. Huang, W.M.; Yang, B.; An, L.; Li, C.; Chan, Y.S. Water-driven programmable polyurethane shape memory polymer: Demonstration and mechanism. Appl. Phys. Lett. 2005, 86, doi: 10.1063/1.1880448.

33. Bothe, M.; Mya, K.Y.; Lin, E.M.J.; Yeo, C.C.; Lu, X.H.; He, C.B.; Pretsch, T. Triple-shape properties of star-shaped POSS-polycaprolactone polyurethane networks. Soft Matter 2012, 8, 965-972.

34. Pretsch, T. Triple-shape properties of a thermoresponsive poly(ester urethane). Smart Mater. Struct. 2010, 19, doi:10.1088/0964-1726/19/1/015006.

35. Sun, L.; Huang, W.M. Mechanisms of the multi-shape memory effect and temperature memory effect in shape memory polymers. Soft Matter 2010, 6, 4403-4406.

36. Zhu, G.M.; Xu, S.G.; Wang, J.H.; Zhang, L.B. Shape memory behaviour of radiation-crosslinked PCL/PMVS blends. Radiat. Phys. Chem. 2006, 75, 443-448.

37. Zhu, G.M.; Xu, Q.Y.; Qin, R.F.; Yan, H.X.; Liang, G.Z. Effect of gamma-radiation on crystallization of polycaprolactone. Radiat. Phys. Chem. 2005, 74, 42-50.

38. Zhu, G.M.; Xu, Q.Y.; Liang, G.Z.; Zhou, H.F. Shape-memory behaviors of sensitizing radiation-crosslinked polycaprolactone with polyfunctional poly(ester acrylate). J. Appl. Polym. Sci. 2005, 95, 634-639.

39. Bhattacharya, K.; James, R.D. The material is the machine. Science 2005, 307, 53-54.

40. Feninat, E.F.; Laroche, G.; Fiset, M.; Mantovani, D. Shape memory materials for biomedical applications. Adv. Eng. Mater. 2002, 4, 91-104.

41. Sun, L.; Huang, W.M.; Lu, H.B.; Wang, C.C.; Zhang, J.L. Shape memory technology for active assembly/disassembly: Fundamentals, techniques and example applications. Assem. Autom. 2014, 34, 78-93.

42. Sun, L.; Huang, W.M.; Wang, C.C.; Ding, Z.; Zhao, Y.; Tang, C.; Gao, X.Y. Polymeric shape memory materials and actuators. Liq. Cryst. 2013, 41, 277-289.

43. Behl, M.; Kratz, K.; Noechel, U.; Sauter, T.; Lendlein, A. Temperature-memory polymer actuators. Proc. Natl. Acad. Sci. USA 2013, 110, 12555-12559.

44. Pretsch, T.; Ecker, M.; Schildhauer, M.; Maskos, M. Switchable information carriers based on shape memory polymer. J. Mater. Chem. 2012, 22, 7757-7766.

45. Kratz, K.; Voigt, U.; Lendlein, A. Temperature-memory effect of copolyesterurethanes and their application potential in minimally invasive medical technologies. Adv. Funct. Mater. 2012, 22, 3057-3065. 
46. Wischke, C.; Lendlein, A. Shape-memory polymers as drug carriers-A multifunctional system. Pharm. Res. 2010, 27, 527-529.

47. Zha, L.S.; Banik, B.; Alexis, F. Stimulus responsive nanogels for drug delivery. Soft Matter 2011, 7, 5908-5916.

48. Lendlein, A.; Behl, M. Shape-memory polymers for biomedical applications. In Smart Materials \& Micro/Nanosystems; Vincenzini, P., Darrigo, G., Eds.; Trans Tech Publications: Pfaffikon, Switzerland, 2008; pp. 96-102.

49. Sokolowski, W.; Metcalfe, A.; Hayashi, S.; Yahia, L.; Raymond, J. Medical applications of shape memory polymers. Biomed. Mater. 2007, 2, S23-S27.

50. Dietsch, B.; Tong, T. A review-Features and benefits of shape memory polymers (SMPs). J. Adv. Mater. 2007, 39, 3-12.

51. Huang, W.M.; Yang, B.; Fu, Y.Q. Polyurethane Shape Memory Polymers; CRC Press: New York, NY, USA, 2011.

52. Ge, Q.; Qi, H.J.; Dunn, M.L. Active materials by four-dimension printing. Appl. Phys. Lett. 2013, 103, doi:10.1063/1.4819837.

53. Ecker, M.; Pretsch, T. Multifunctional poly(ester urethane) laminates with encoded information. RSC Adv. 2014, 4, 286-292.

54. Fritzsche, N.; Pretsch, T. Miniaturization of QR code carriers based on shape memory polymer. In Proceedings of the Asme Conference on Smart Materials, Adaptive Structures and Intelligent Systems, Snowbird, UT, USA, 16-18 September 2013; pp. 81-88.

55. Ecker, M.; Pretsch, T. Durability of switchable QR code carriers under hydrolytic and photolytic conditions. Smart Mater. Struct. 2013, 22, doi:10.1088/0964-1726/22/9/094005.

56. Gu, Z.Z.; Uetsuka, H.; Takahashi, K.; Nakajima, R.; Onishi, H.; Fujishima, A.; Sato, O. Structural color and the lotus effect. Angew. Chem. Int. Ed. 2003, 42, 894-897.

57. Hong, S.H.; Hwang, J.; Lee, H. Replication of cicada wing's nano-patterns by hot embossing and UV nanoimprinting. Nanotechnology 2009, 20, doi:10.1088/0957-4484/20/38/385303.

58. Miaudet, P.; Derré, A.; Maugey, M.; Zakri, C.; Piccione, P.M.; Inoubli, R.; Poulin, P. Shape and temperature memory of nanocomposites with broadened glass transition. Science 2007, 318, 1294-1296.

59. Huang, W.M.; Lu, H.B.; Zhao, Y.; Ding, Z.; Wang, C.C.; Zhang, J.L.; Sun, L.; Fu, J.; Gao, X.Y. Instability/collapse of polymeric materials and their structures in stimulus-induced shape/surface morphology switching. Mater. Design 2014, 59, 176-192.

60. Everhart, M.C.; Nickerson, D.M.; Hreha, R.D. High-temperature reusable shape memory polymer mandrels. In Smart Structures and Materials 2006: Industrial and Commercial Applications of Smart Structures Technologies; White, E.V., Davis, L.P., Eds.; Society of SPIE: Bellingham, WA, USA, 2006; Art. No. 61710K.

61. Felton, S.M.; Tolley, M.T.; Shin, B.; Onal, C.D.; Demaine, E.D.; Rus, D.; Wood, R.J. Self-folding with shape memory composites. Soft Matter 2013, 9, 7688-7694.

62. Ionov, L. Soft microorigami: Self-folding polymer films. Soft Matter 2011, 7, 6786-6791.

63. Zhao, Y.; Huang, W.M.; Wang, C.C. Thermo/chemo-responsive shape memory effect for micro/nano surface patterning atop polymers. Nanosci. Nanotechnol. Lett. 2012, 4, 862-878. 
64. Sun, L.; Zhao, Y.; Huang, W.M.; Purnawali, H.; Fu, Y.Q. Wrinkling atop shape memory materials. Surf. Rev. Lett. 2012, 19, doi:10.1142/S0218625X12500102.

65. Huang, W.P.; Cheng, H.H.; Fedorchenko, A.I.; Wang, A.B. Strain on wrinkled bilayer thin film. Appl. Phys. Lett. 2007, 91, doi:10.1063/1.2767204.

66. Bowden, N.; Brittain, S.; Evans, A.G.; Hutchinson, J.W.; Whitesides, G.M. Spontaneous formation of ordered structures in thin films of metals supported on an elastomeric polymer. Nature 1998, 393, 146-149.

67. Chen, X.; Hutchinson, J.W. A family of herringbone patterns in thin films. Scr. Mater. 2004, 50, 797-801.

68. Chan, E.P.; Crosby, A.J. Fabricating microlens arrays by surface wrinkling. Adv. Mater. 2006, 18, 3238-3242.

69. Zhao, Y.; Wang, C.C.; Huang, W.M.; Purnawali, H.; An, L. Formation of micro protrusive lens arrays atop poly(methyl methacrylate). Opt. Express 2011, 19, 26000-26005.

70. Chiodo, J.D.; Billett, E.H.; Harrison, D.J. Active disassembly. J. Sustain. Prod. Des. 1998, 4, 26-36.

71. Chiodo, J.D.; Anson, A.W.; Billett, W.H.; Harrison, D.J.; Perkins, M. Eco-design for active disassembly using smart materials. In Proceedings of the Second International Conference on Shape Memory and Superelastic Technologies (SMST), Pacific Grove, CA, USA, 2-6 March 1997; pp. 269-274.

72. Chiodo, J.D.; Billett, E.H.; Harrison, D.J. Active disassembly using shape memory polymers for the mobile phone industry. In Proceedings of the 1999 IEEE International Symposium on Electronics and the Environment (ISEE 1999), Danvers, MA, USA, 11-13 May 1999; pp. 151-156.

73. Chiodo, J.; Jones, N. Smart materials use in active disassembly. Assem. Autom. 2012, 32, 8-24.

74. Purnawali, H.; Xu, W.W.; Zhao, Y.; Ding, Z.; Wang, C.C.; Huang, W.M.; Fan, H. Poly(methyl methacrylate) for active disassembly. Smart Mater. Struct. 2012, 21, doi:10.1088/0964-1726/ 21/7/075006.

75. Garcia, J.; Jones, G.; Virwani, K.; McCloskey, B.; Boday, D.; ter Huurne, G.; Horn, H.; Coady, D.; Bintaleb, A.; Alabdurahman, A.; et al. Recyclable, strong thermodest and organogels via paraformaldehyde condensation with diamines. Science 2014, 344, 732-735.

(C) 2014 by the authors; licensee MDPI, Basel, Switzerland. This article is an open access article distributed under the terms and conditions of the Creative Commons Attribution license (http://creativecommons.org/licenses/by/3.0/). 